\title{
Nuevas evidencias del cristianismo en Asturias: los crismones de la villa romana de Veranes (Gijón)
}

\author{
Carmen Fernández OchoA \\ Universidad Autónoma de Madrid \\ carmen.fernandez@uam.es \\ Fernando Gil SendinO \\ Universidad Autónoma de Madrid \\ fsendino66@gmail.com \\ Javier SALIDo DomíngUEZ \\ Escuela Española de Historia y Arqueología en Roma- CSIC \\ pjaviers@hotmail.com
}

Recibido: 19 de abril de 2013

Aceptado: 21 de septiembre de 2013

\section{RESUMEN}

En este trabajo se presentan unos grafitos con anagramas cristianos realizados sobre sillares de arenisca extraídos de la obra arquitectónica de la villa romana de Veranes. El sillar con mayor número de grabados se reutilizó en una tumba de la necrópolis que ocupó el espacio de la villa a partir del siglo V d.C. Los análisis óseos del enterramiento nos permiten datar el momento de uso de esta tumba en el periodo tardoantiguo, así como plantear una reflexión sobre el primitivo cristianismo en Asturias.

Palabras clave: Villa romana. Gijón (Asturias). Transformación de villas tardorromanas. Primer cristianismo. Crismones.

\section{New evidences of early Christianity in Asturias: christograms of the roman villa of Veranes (Gijón)}

\begin{abstract}
This paper deals with the graffiti containing Christian anagrams on sandstone blocks found in the Roman villa of Veranes (Gijón, Asturias). Ashlars with various engravings were reused in a tomb in the necropolis that occupied the space of the villa from the fifth century A.D. The analysis of the buried bones indicates that the tomb dates back to the Late Antiquity period and allows us to reflect on early Christianity in Asturias.
\end{abstract}

Key words: Roman villa. Gijón (Asturias). Changes of Late Roman villas. Early Christianity. Christograms.

Sumario: 1. Veranes: entre la Tardía Antigüedad y la Edad Media. 2. Los crismones de Veranes y su contexto arqueológico. 3. Veranes y la implantación del cristianismo en Asturias. 


\section{Veranes: entre la Tardía Antigüedad y la Edad Media}

Las excavaciones desarrolladas en los últimos años en la villa romana de Veranes (Asturias) han puesto de manifiesto una larga secuencia de ocupación de este asentamiento rural que estuvo en pleno funcionamiento desde época flavia hasta mediados o finales del siglo V d.C. ${ }^{1}$ El espacio ocupado por la villa monumental sufrió diversas transformaciones durante la Tardía Antigüedad y continuó parcialmente ocupado hasta el final de la Edad Media. ${ }^{2}$

Uno de los aspectos que mayor interés ha suscitado en la historiografía reciente del mundo rural romano de época tardía ha sido la búsqueda de datos que expliquen el fin de las villae tardorromanas y su pervivencia o reutilización durante los oscuros tiempos de la transición entre la Tardía Antigüedad y el Medievo. ${ }^{3}$ En el centro de estas cuestiones se encuentra la emergencia de nuevas creencias entre las que la difusión del Cristianismo adquiere total protagonismo bien sea como fenómeno individual ${ }^{4}$ o colectivo. ${ }^{5}$ La superposición del tiempo sobre un mismo espacio se aprecia en el conocimiento que hoy en día tenemos de numerosas villae, cuyos restos arquitectónicos se transformaron para convertirse en iglesias primitivas, parroquias o monasterios. ${ }^{6}$ En el primero de estos ejemplos, dentro de la diversidad de adaptaciones funcionales y arquitectónicas documentadas, es frecuente que el centro de culto ocupe alguna de las estancias de la propia villa y su necrópolis se extienda por las habitaciones contiguas, como sucede en el caso de Veranes. Otras veces, estas primitivas iglesias se ubican en las inmediaciones del espacio ocupado por la villa, pero formando una construcción independiente como ocurre, por ejemplo, en el yacimiento bracarense de S. Martinho Dumiense. ${ }^{7}$

Estos importantes procesos históricos, relacionados con la implantación del Cristianismo en lugares previamente ocupados en época romana, ha sido objeto de estudio desde hace años en la mayoría de los dominios que abarcó el Imperio Romano, bien se trate de áreas urbanas o rurales. ${ }^{8}$ Desde una perspectiva fundamentalmente arqueológica, las fluctuaciones temporales y las implicaciones espaciales del fenómeno cristiano también se han estudiado últimamente en el cuadrante noroccidental de la Península Ibérica mediante el análisis de la evolución topográfica y funcional de los núcleos urbanos y rurales durante la tardía Antigüedad Tardía. ${ }^{9}$

1 Este trabajo se ha realizado en el marco del proyecto $\mathrm{I}+\mathrm{D}$ de investigación: Paisajes de dominación y resistencia. Procesos de apropiación y control social y territorial en el Noroeste hispano (Padore) (HAR2012-33774) dirigido por A. Orejas Saco del Valle.

2 En este apartado seguimos básicamente nuestros trabajos anteriores: Fernández OchoA - Gil SENDINo 1999; Fernández OchoA - Gil Sendino - Orejas 2004; Fernández OchoA - Gil Sendino 2007; Fernández OchoA - Gil Sendino 2007a; Fernández OchoA - Gil Sendino 2007b; Fernández OchoA - Gil Sendino 2008; Fernández OchoA - Gil Sendino 2009; Fernández OchoA - Gil Sendino 2011.

3 Brogiolo (ed.), 1997.

4 VV. AA. 2000.

5 CAMPIONE 2000.

6 Godoy 1995; Ripoll - Arce 1999; Ripoll - VelázQuez 1999; LóPez Quiroga - Rodríguez Martín 2001; Chavarría 2004; Chavarría 2006; Oepen 2012.

7 FONTES 1991-1992.

8 Brogiolo - Chavarría 2005; Brogiolo et alii 2005.

9 Fernández Ochoa et alii 2005; Gutiérrez 2008. 
En el caso de Asturias, la investigación sobre el fin de la romanidad y los años subsiguientes apenas ha sido tratada hasta tiempos recientes. Ante la ausencia de excavaciones rigurosas, siempre se ha enfocado este tema desde la escueta información textual aderezada con los escasos hallazgos aislados depositados en el Museo Arqueológico de Asturias. ${ }^{10}$ Hace años Diego Santos recopiló las inscripciones que acompañan a algunos restos visigodos ${ }^{11} \mathrm{y}$ más adelante se han publicado algunos estudios de gran interés basados en los análisis de las fuentes textuales. ${ }^{12} \mathrm{~A}$ partir de estas aportaciones, la imagen de Asturias para este periodo siempre ha resultado fragmentaria y oscura debido a la falta de investigaciones arqueológicas capaces de ofrecer una visión renovada de esta importante cuestión histórica, tal y como subrayamos hace ya bastantes años ${ }^{13} \mathrm{y}$ así ha sido considerada también por otros autores. ${ }^{14}$ En este sentido y, desde un enfoque eminentemente arqueológico, debemos de considerar el último y documentado trabajo de A. Gutiérrez ${ }^{15}$ como un nuevo punto de partida para acometer el análisis detallado de las evidencias arqueológicas que muestran el contexto de las fases de transición entre el final del Imperio Romano y los momentos iniciales del Medievo en Asturias. Este autor señala que una de las aportaciones más elocuentes acerca de esta compleja etapa histórica en Asturias procede de las investigaciones que hemos realizado en Gijón ${ }^{16}$ y en la villa romana de Veranes ${ }^{17}$ a las que debemos agregar los últimos estudios realizados en este yacimiento ${ }^{18}$ y los que se ofrecen en el presente trabajo.

\section{Los crismones de Veranes y su contexto arqueológico}

Los testimonios que se presentan a continuación corresponden a dos sillares de arenisca que contienen símbolos cristianos, pero que proceden de dos lugares distintos. El que denominaremos "crismón de la Abadía" se encuentra actualmente en la puerta de acceso a la sacristía de la actual Abadía de Cenero, a pocos kilómetros de la villa romana de Veranes y fue llevado a este lugar por el párroco de Cenero, D. Manuel Valdés Gutiérrez a mediados del siglo XX. El segundo sillar se halló en el transcurso de las excavaciones de la villa de Veranes en el año 2008 y a él nos referiremos en primer lugar habida cuenta, no sólo de su mayor interés iconográfico, sino también de la significativa documentación arqueológica que hemos podido obtener para su estudio.

\footnotetext{
10 Diego Santos 1979; Jiménez Garnica 1992.

11 Diego Santos 1994.

12 Besga Marroquín 2000; Besga Marroquín 2010; Calleja 2005.

13 Fernández Ochoa 1982, 320 ss.

14 Menéndez Bueyes 2001, 231 ss.

15 GuTIÉRREZ 2010.

16 FernÁndez OchoA 2003; FERnÁndez OchoA 2010.

$17 \mathrm{Vid}$. nota 2

18 Fernández Ochoa et alii 2012.
} 
2.1. El sillar con crismones de la tumba 593 de la necrópolis de Veranes

El sillar con crismones encontrado en la necrópolis de la villa se localizó en el denominado Patio Norte que se extiende desde la entrada principal de la pars urbana hasta un amplio espacio de representación levantado al este del complejo arquitectónico. Esta extensa superficie, de unos $700 \mathrm{~m}^{2}$, permite el acceso a las edificaciones que definen el área de servicio de la villa donde se ha identificado un horreum ${ }^{19}$ y una edificación que contenía la cocina y el horno domésticos. Al sur del patio, se llega a las dos entradas que comunicaban tanto con los ambientes de la zona más occidental del complejo áulico como con el pasillo porticado abierto al mediodía que conducía a las estancias del sector oriental de la vivienda (Fig. 1).

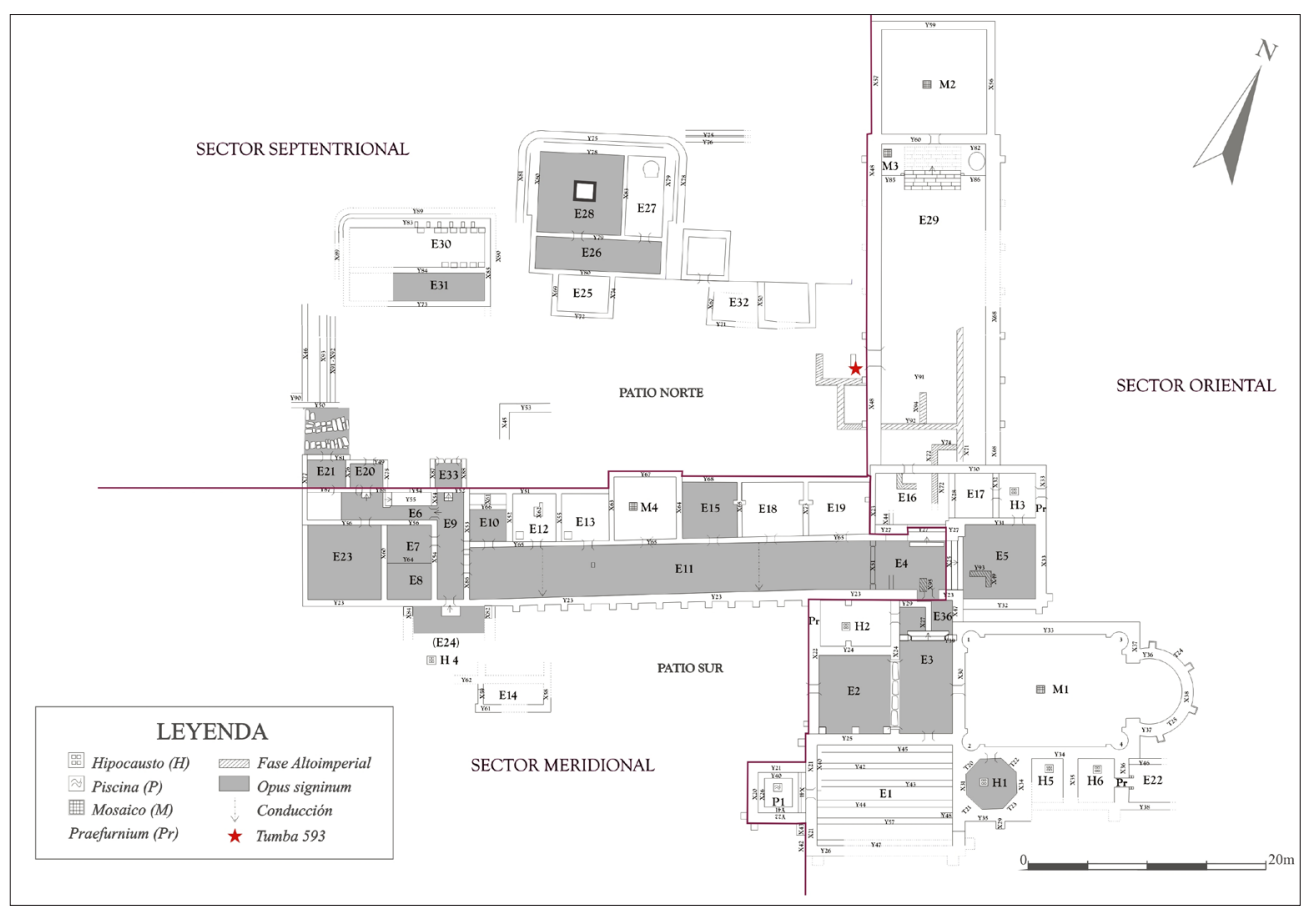

Fig. 1. Planta general de la villa de Veranes con indicación del lugar del hallazgo de sillar con crismones (T 593).

El aspecto general del patio, tal como lo conocemos hoy en día, es fruto de las distintas reformas llevadas a cabo en la villa entre finales del siglo III d.C. y la segunda mitad del siglo IV d.C. De esta forma, durante la segunda mitad de la cuarta centuria, se levanta en el extremo oriental del Patio Norte un amplio conjunto de ambientes

19 Fernández Ochoa et alii 2012. 
articulados a partir de complejas combinaciones de escaleras, estancias y arcos que conforman un teatral espacio de representación que confiere al conjunto una notable monumentalidad. ${ }^{20}$ Dentro de este conjunto de aspecto palacial, la estancia E 29 conservaba los restos de un umbral que comunicaba el Patio Norte con las estancias de carácter más ceremonial. Según los restos conservados, este acceso estaba construido con sillares de arenisca en su basamento y jambas. Por sus dimensiones, con un paso de 2,90 $\mathrm{m}$ de anchura, la puerta debió mantener cierta monumentalidad y no es improbable que estuviera definida a partir de un arco de medio punto.

Todo el espacio ocupado por el Patio Norte se ha excavado en varias fases desde 1998. En el año 2007 iniciamos la última campaña en este sector y acometimos el registro arqueológico de la zona oriental de dicho patio. En general, la secuencia estratigráfica no difiere de la de otros sectores del yacimiento. Se han podido individualizar los restos constructivos de una instalación altoimperial y las estructuras correspondientes al complejo rural tardorromano. Asimismo, en la zona más oriental del patio, se han encontrado restos de un área de actividad metalúrgica relacionada con el trabajo del hierro, prolongación de la documentada bajo la estancia E 29. ${ }^{21}$

Por otro lado, aunque se han individualizado algunas unidades arqueológicas que se corresponden con acciones y depósitos romanos, el desarrollo del cementerio en este sector ha alterado profundamente el registro arqueológico. En total se exhumaron en el sector oriental del Patio Norte, entre el año 2007 y el 2008, unas 85 tumbas pertenecientes a la necrópolis tardoantigua y medieval instalada sobre las ruinas de la antigua villa romana. Estos enterramientos presentan características similares a las localizadas en otras zonas del yacimiento. Las inhumaciones se realizaron siempre con los cuerpos depositados en posición de decúbito supino, con el cráneo situado al oeste del enterramiento. Las tumbas exhumadas en este sector son todas de fosa, aunque la mayoría presentaban el interior de la sepultura forrada con piedras y lajas a modo de cista. Los enterramientos son individuales, pero con frecuencia se evidencian tumbas que presentan reutilizaciones y donde los restos del primer individuo aparecen a los pies o junto a la cabeza de la nueva deposición.

Algunas de las tumbas más próximas al umbral de E 29 presentaban, formando parte de su cista, fragmentos de piedras areniscas y sillares que debieron pertenecer a las jambas del acceso a esta estancia, tal como se atestigua en las tumbas 592, 593 y 608. Entre éstas destaca la tumba 593 (Fig. 2) situada junto al umbral, un enterramiento con la cista construida con cinco fragmentos de sillares de arenisca procedentes del edificio romano. La cobertera o tapa de la inhumación estaba constituida por dos grandes lajas calizas y una tercera más pequeña que rellenaba el hueco entre las dos grandes piedras. El interior de la fosa aparecía prácticamente colmatado con el relleno procedente de la excavación de la propia tumba sobre las unidades arqueológicas romanas. Esta circunstancia explica que dicho relleno presentara una matriz mixta y contuviera algunos materiales muy fragmentados de TSH y cerámica común romana. Los restos humanos recuperados en el enterramiento se encontraban muy mal conservados. Se han podido identificar restos óseos de al menos dos individuos

20 Fernández Ochoa - Gil Sendino 2006 passim; Fernández OchoA - Gil Sendino 2008, 445.

21 Fernández OchoA - Gil Sendino 2008, 442. 


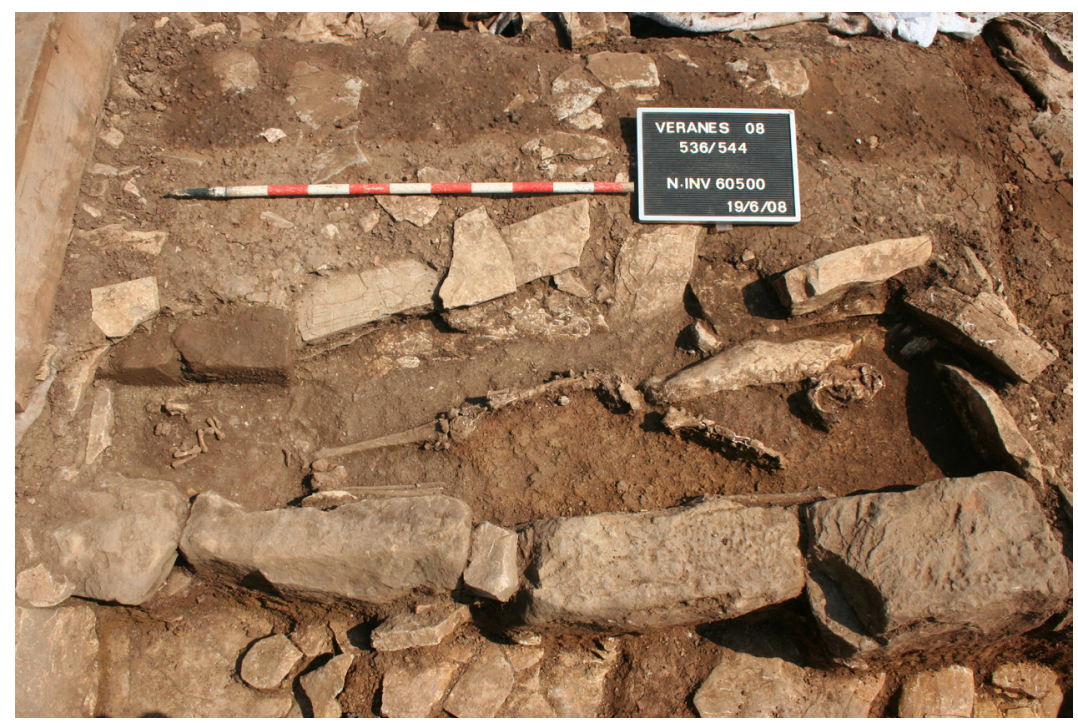

Fig. 2. Detalle de la tumba 593.

adultos de sexo no determinable. Se cogieron muestras de los dos individuos para obtener dataciones radiocarbónicas. Lo más probable es que el primer individuo se enterrara durante el siglo VIII y la reutilización de la tumba se produjera entre los siglos VIII y X d.C. ${ }^{22}$

Como ya hemos expuesto, la tumba 593 contaba con una cista de varios fragmentos de piedras, de las cuales cinco eran areniscas procedentes de la amortización y ruina del edificio tardorromano. En la cara norte del enterramiento, una de estas piedras de arenisca era un sillar procedente de la jamba de una puerta, lo más probable extraída del acceso localizado en E 29 que comunicaba con el Patio Norte. Este sillar, de unos 0,75 $\mathrm{m}$ de ancho, 0,30 $\mathrm{m}$ de alto y unos $0,20 \mathrm{~m}$ de profundidad, presenta en su cara vista varios grafitos que reproducen al menos cuatro crismones o criptogramas (. 3 y 4). Se trata de representaciones muy esquemáticas, practicadas mediante incisión sobre el sillar, que responden a dos tipos distintos: los primeros (situados a la derecha de la imagen) son cristogramas (chi: 17x10 cm; rho: 17x10,5 cm; rho: 14,5x4,1 cm) que cuentan con las dos letras, la X (chi) y la $\mathrm{P}$ (rho), intercaladas verticalmente, determinando una posición simétrica de dos aspas oblicuas de la chi mientras que la rho se adhiere a una de las aspas de la cruz. Estos crismones de tipo constantiniano se han fechado tradicionalmente a partir del siglo IV d.C. en Hispania, al igual que las cruces monogramáticas, ${ }^{23} \mathrm{y}$ ambos símbolos se alternan y su uso es coetáneo. ${ }^{24}$ Los otros dos símbolos representados en el sillar, a la izquierda de la imagen, $(11 \times 10 \mathrm{~cm}$;

\footnotetext{
22 CNA 362: 685-974 (99 \% a 2 б) / CNA 361: 771-979 (98 \% a $2 \sigma)$.

23 VIVES 1969, 9.

24 Cerrillo 1974, 453.
} 


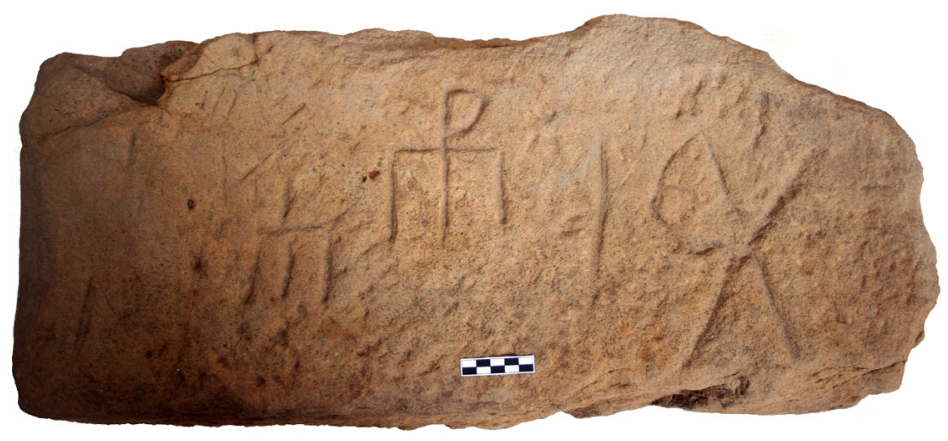

Fig. 3. Sillar con crismones de la tumba 593.

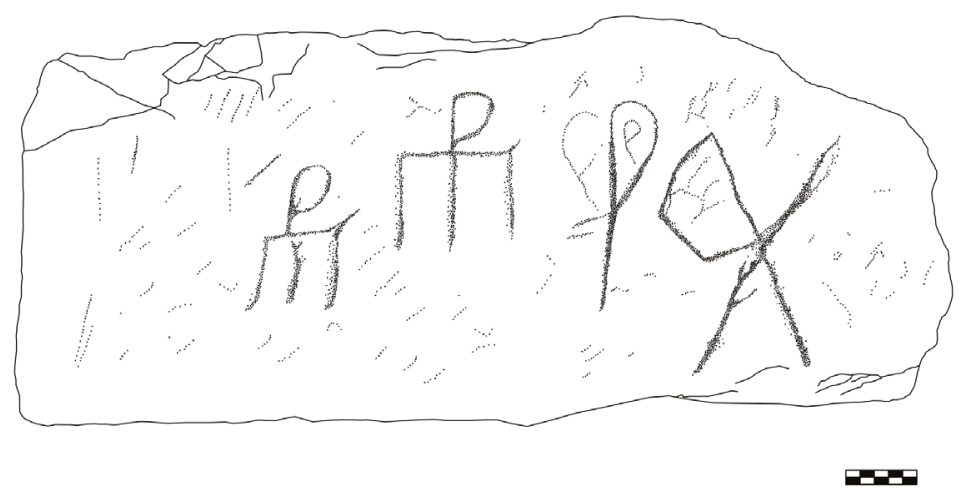

Fig. 4. Dibujo del sillar con crismones de la tumba 593.

$10,2 \times 8,1 \mathrm{~cm}$ ) mucho menos frecuentes en las representaciones cristianas, presentan una rho perfectamente marcada, situada por encima de tres trazos cursivos paralelos.

Los crismones, ampliamente representados en todo tipo de soportes desde el siglo IV d.C., cuando Constantino toleró el culto del Cristianismo después del Edicto de Milán del año 313 d.C., ${ }^{25}$ están constituidos por las letras griegas X y P, que corresponden a las dos primeras del nombre de Cristo en griego (X Posiblemente la representación abreviada del Labarum constantiniano pasó a constituir desde estos primeros momentos un emblema del monarca o marca del poder imperial. ${ }^{26}$

25 Los primeros testimonios se fechan a partir de la segunda mitad del siglo IV d.C. (Grossi Gondi 1920, 64-65). En el caso de Hispania está ampliamente representado en diferentes tipos de soportes, en inscripciones sepulcrales, tegulae, terra sigillata, etc. desde finales de esta centuria (HüBNER 1900).

26 A comienzos del siglo IV d.C., el crismón se convertirá en el símbolo de Cristo, aunque mantiene su sentido de abreviación, especialmente en lápidas funerarias. Es seguramente con la aparición del "Lábaro de 
La particularidad de los símbolos situados en la parte derecha del sillar encontrado en Veranes es el esquematismo de las representaciones que comportó la incisión de la rho en el lado izquierdo del aspa, formado por la $\mathrm{X}$ en una de las grafías, y la escasa incisión de la $\mathrm{X}$ en la otra representación, de modo que se distingue prácticamente una rho individual, en lugar de un crismón constantiniano completo. No se representa en este sillar ni el crismón delimitado por una láurea, que aparece a mediados del IV d.C., como símbolo de la victoria de Cristo sobre la muerte, ${ }^{27}$ ni tampoco la rho ha sido sustituida por la tau o por una pequeña cruz latina, como a veces sucede.

En cuanto a la datación de los crismones del primer tipo del sillar de Veranes, pueden fecharse entre finales del siglo $\mathrm{V}$ d.C., que coincide con el momento de abandono de la villa romana, y el siglo VIII d.C., datación obtenida por C-14 para el primer individuo inhumado en la tumba 593. Este tipo de cristogramas simples son frecuentes en representaciones cristianas procedentes del entorno de Roma y datadas en momentos anteriores, entre finales del siglo IV d.C. y comienzos del V d.C. Se han localizado en lugares tan emblemáticos como la catacumba de Panfilo en Roma donde además de cruces, son numerosos los crismones de este tipo. ${ }^{28}$ También se realizaron mediante incisión crismones que acompañan el texto del difunto, con indicación de la edad de su fallecimiento, en el cierre de algunas tumbas de la catacumba de la Ex Vigna Chiaraviglio, próxima a la Appia Antica (Fig. 5a). ${ }^{29}$

El amplio arco cronológico que encierran los crismones de Veranes se puede aquilatar más a partir de otras evidencias como, por ejemplo, los grabados, las inscripciones y otras representaciones de cristogramas plasmadas en manuscritos. En este sentido, el tipo de grafía de los crismones de Veranes se asemeja notablemente a las inscripciones en soporte pétreo fechadas entre los siglos VI y VII d.C. en Hispania, en concreto, en las pizarras de época visigoda, ${ }^{30}$ muchas de las cuales se fechan en

Constantino" cuando el cristograma adquiere la función de símbolo. Tal y como nos relata Eusebio de Cesarea, Constantino, antes de enfrentarse a la batalla del Puente Milvio en Roma en el año 312 d.C., en la que derrotó a Majencio, hizo una ferviente oración a Dios. El Señor le premió con la visión importantísima de un signo y las palabras: "con este signo vencerás". De noche, en una nueva visión, recibe el encargo de hacer un lábaro, o bandera, con aquella señal o símbolo. El lábaro que mandó hacer se componía del asta y una corona dentro de la cual se superponían las letras griegas rho y chi, caracteres que al quedar superpuestos tenían la forma de una "cruz decusata". Desde ese momento constituirá una insignia militar, tanto en los lábaros, banderas o estandartes (Girardet 2010, 52-62), como en otros objetos, como es el caso de los escudos (Delgado 1984, 87, nota 6). Los estudios numismáticos de Bruun concluyen que posiblemente el labarum se convirtió en un emblema del monarca o marca del poder imperial a partir del año 320 d.C. (BRuun 1966, 61-64). Sobre su representación y uso en estandartes y representación en monedas, véase TRAVIANI 2007.

27 El epígrafe de Flavio Anastasio de Rávena es una de las representaciones más antiguas del cristograma, fechada antes de mediados del siglo IV d.C. (CIL IX, 323; FarIoLI 1977, 243). En Hispania son representados en el siglo VI d.C. como en el cancel de la villa de Fortunatus que formaba parte de las instalaciones litúrgicas de la iglesia (SCHLunCK - Hauschild 1978, 162-163).

28 Mazzoleni 1996, 111.

29 La inscripción visible en la galería Q10 de dicho complejo dice exactamente: [d]epositus / [cruz] $o b<i>t a /$ anno[rum?...] (PoDd 2009, 553, $\mathrm{n}^{\circ}$ 11, fig. 12).

30 Una de las pizarras procedentes de Galinduste (Salamanca), que presenta un crismón, se ha podido fechar en el siglo VI d.C., en el año 586 d.C. (Velázquez 2004, 150-152, nº 8); otras con crismón localizadas en el mismo lugar se han datado en los siglos VI o VII d.C. (VelázQuez 2004, 165-168, $\mathrm{n}^{\circ} 11 ; 416-418, \mathrm{n}^{\circ}$ 124). La pizarra de Santibáñez de la Sierra (Salamanca) con dos crismones en la cara posterior se ha fechado en el siglo VII d.C. (VelázQuez 2004, 127-131, nº 4); también en este siglo se ha datado la pizarra de Pelayos 


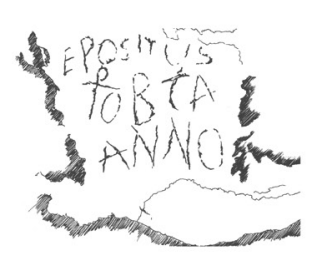

a

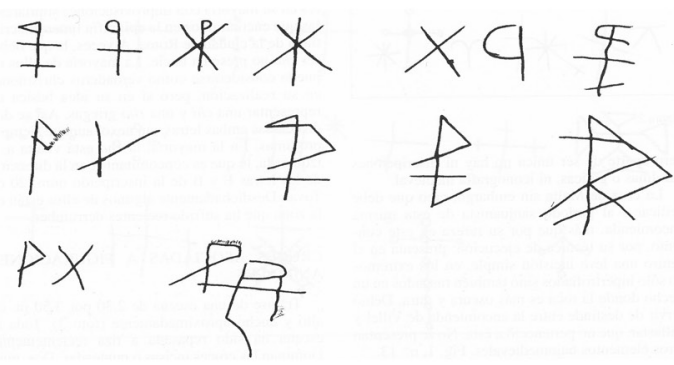

b

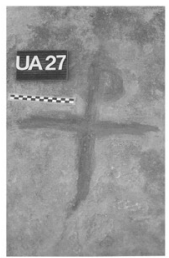

$\mathrm{c}$

Fig. 5. a- Cierre de una tumba de la galería Q10 de las catacumbas del complejo de San Sebastián, próximas a la Appia Antica, según PodDi (2009, 553, n 11, fig. 12); b- Crismones grabados en Peñalba de Villastar (Teruel), según Pérez Vilatela (1995, fig. 3); c- Criptograma de la segunda necrópolis episcopal de Valencia, según Calvo $(2000,201)$.

el siglo VII d.C. Igualmente podemos relacionar las trazas de nuestro sillar con el grabado G/4 localizado en el interior de la cueva alavesa de Las Gobas $6^{31}$ y con los crismones realizados en los pergaminos de finales de la séptima centuria, aunque obviamente el contexto de estos ejemplares es diferente y, en el caso asturiano, aparecen de forma aislada. ${ }^{32}$ No obstante, según la tipología establecida por Eisenlohr, cristogramas similares aparecidos en Hispania se podrían situar a lo largo del siglo VI d.C. ${ }^{33}$ e incluso en momentos anteriores, como los grabados interpretados como crismones localizados en Peñalba de Villastar (Teruel), ${ }^{34}$ aunque estos últimos no son tan semejantes a los aparecidos en Veranes (Fig. 5b). Crismones tan esquemáticos como los practicados en el sillar de Veranes se han localizado también en tumbas de la segunda necrópolis episcopal de Valencia, correspondiente a la segunda fase de enterramientos, fechados en el siglo VII d.C. ${ }^{35}$ (Fig. 5c). Conviene recordar, por otro lado, que desde el siglo V d.C., pero sobre todo entre el VI y el VII d.C., es el

(Salamanca) con un crismón similar (VelázQuez 2004, 184-185, nº 20). Las encontradas en Diego Álvaro (Ávila), con crismones muy parecidos a los de Veranes, se han fechado entre finales del siglo VI d.C. y comienzos del VII d.C. (c. 586-601 d.C.; VelÁzquez 2004, 234-239, nº 41; 274-279, nº 49; 288-291, nº 54; 294, no 56; 305-307, n⿳0 61), en la primera mitad del siglo VII d.C. (VelázQUEz 2004, 219-234, n 40; 299-304, $\left.n^{\circ} 59 ; 348-353, n^{\circ} 97\right)$ y en la segunda mitad de este siglo (VeLÁzQUEZ 2004, 260-268, $n^{\circ} 46 ; 272-274, n^{\circ} 48$ ). A finales del siglo VII d.C. se ha datado la pizarra procedente de Martínez (Ávila; VelÁzQuEz 2004, 345-346, $n^{\circ}$ 94); en este siglo se fechan también las aparecidas en Sotoserrano (Ávila; VelÁzQUEz 2004, 397, $n^{\circ} 116$ ), en Navahombela (Salamanca; VelázQuez 2004, 440-442, $\mathrm{n}^{\circ} 135 ; 442-443, \mathrm{n}^{\circ} 136$ ) y Huerta (Salamanca; VelÁZQueZ 2004, 450-451, nº 142; 468-469, nº 159).

31 En el interior de la cueva alavesa Las Gobas 6, se ha documentado un crismón (G/4), que se ha podido fechar entre finales del siglo VI y finales del VII d.C. (AzKarate 1988, 391, 397 y 475-478).

32 Ruiz Asencio 2005, 228-230.

33 EisEnlohr 1994, tabla 1, nº 2-3. También en la necrópolis del castro de Yecla de Yeltes se han localizado cierres de tumbas del siglo VI d.C. con crismones similares (Martín VALls 1982).

34 Pérez Vilatela 1995, 205, fig. 3.

35 Calvo 2000, 201. 
momento en que se produce una eclosión de la organización religiosa en el ámbito rural del Mediterráneo Occidental. ${ }^{36}$ En definitiva, el esquematismo de los crismones del primer tipo del sillar asturiano, con los paralelos anteriormente citados, se puede fechar de manera hipotética en el momento más tardío del uso original del soporte, es decir, el siglo VII d.C.

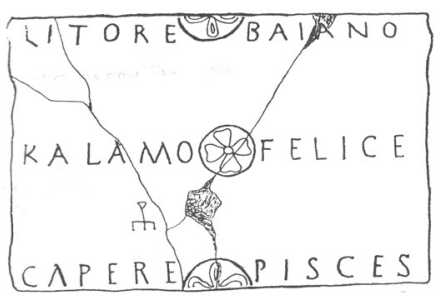

a

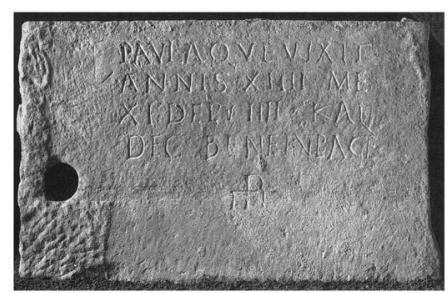

b

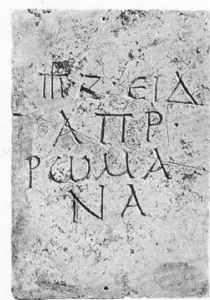

C

Fig. 6. a- Lápida con inscripción y monograma, según FerruA (1947, 136); b- Epígrafe de Paula en el espacio Fv de las catacumbas del complejo de San Sebastián, próximo a la Appia Antica, según GiUliani et alii (2001, 181-183, A.a.6, fig. 61); c- Inscripción griega de Romana, de la catacumba de Calepodio, según Nestori (1985, fig. 2).

El segundo tipo de cristogramas del sillar de Veranes, mucho menos frecuente en el registro arqueológico, cuenta con tres trazos cursivos paralelos en la parte inferior. En alegorías similares, se representan en los apéndices laterales, a ambos lados de la rho, las letras $\alpha$ (alfa) y $\omega$ (omega), la primera y la última del alfabeto griego, que simbolizan a Cristo como principio y fin de todas las cosas (Apocalipsis, 1, 8). Las representaciones más antiguas, similares a los crismones del segundo tipo de Veranes, se encuentran en inscripciones sepulcrales cristianas extrapeninsulares. Ferrua nos informa de la aparición de una inscripción con el texto: litore baiano / kalamo felice / capere pises, y entre las dos últimas líneas se reproduce un cristograma ${ }^{37}$ muy similar al realizado en el sillar encontrado en Veranes (Fig. 6a). Según la interpretación de Ferrua, la lápida pudo servir de juego de mesa hasta que posteriormente fue reutilizada para la construcción del sepulcro de uno de los primeros cristianos. ${ }^{38}$ Esta misma tipología aparece en las ya citadas catacumbas de Ex Vigna Chiaraviglio, junto al complejo de San Sebastián, en la vía Appia Antica, cuya datación se fija entre la segunda mitad del siglo IV y principios del V d.C. ${ }^{39}$ (Fig. 6b) y en la catacumba de

36 Colin 2008, 214-216.

37 Ferrua 1947, 136.

38 Ferrua 1947a, 495.

39 La lastra de mármol blanco constituye con toda probabilidad al cierre del pozo 96 del espacio Fv y en ésta se puede leer: Paula que vixit / annis XIIII me(nses) / XI dep(osita) IIII kal(endas) / Dec(embres) bene(merens) in pace (Giuliani et alii 2001, 181-182, nº A.a.6, fig. 61). 


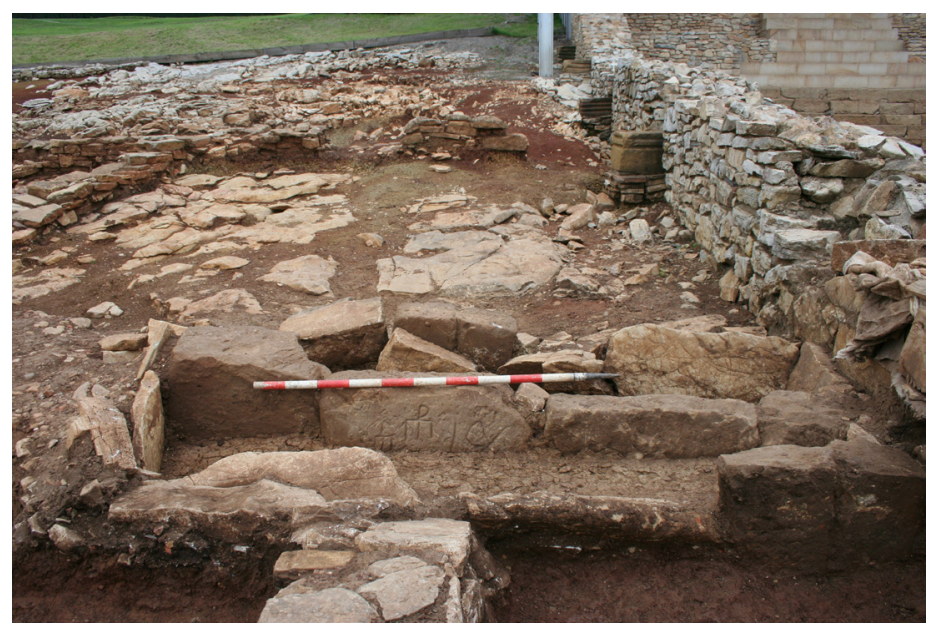

Fig. 7. Detalle de la excavación de la tumba 593 con la situación del sillar reutilizado.

Calepodio (Fig. 6c). ${ }^{40}$ No obstante, el anagrama de Veranes, con un ductus cursivo de trazo sencillo, se asemeja claramente al tipo de escritura de época visigoda de los siglos VI y, sobre todo, VII d.C., como podemos observar en las pizarras de este periodo. También es semejante a la cruz griega con tres trazos inferiores grabada en Peñalba de Villastar (Teruel), ${ }^{41}$ posiblemente fechadas en este mismo periodo, siglo VI d.C., cuando las cruces radiales de brazos iguales "griegas" sustituyen a los crismones y las cruces monogramáticas. ${ }^{42}$ Por otro lado, los cristogramas de este segundo tipo de Veranes son similares al crismón grabado en la inscripción colocada en la puerta de acceso, quizás principal, a un monasterio de religiosas en el año 651 d.C. o 661 d.C. ${ }^{43}$ y descubierta en las inmediaciones de la iglesia de Santa María de Eulalia de Mérida. En este caso, del crismón penden las dos letras griegas que no encontramos en el sillar asturiano. ${ }^{44}$ También es parecido al representado en la inscripción griega aparecida en Mértola ${ }^{45}$ que cuenta además con las dos letras de inicio y fin del alfabeto griego. Otros monogramas procedentes de zonas próximas al anterior se

40 La inscripción griega va precedida de un criptograma similar al del sillar de Veranes (NESTORI 1985, 237-239, fig. 2).

41 Pérez Vilatela 1995, 206-207, fig. 4.

42 Pérez Vilatela 1995, 207.

43 Los especialistas que han estudiado la inscripción ofrecen dos posibles lecturas del numeral, según se interprete la existencia de un nexo LX (FITA 1894, 83; SASTRE 2010, 18, fig. 2) o se considere que se trata de una prolongación de la X que debe entenderse como XL (Navascués 1931, 10; Ramírez Sádaba - Mateos 2000, 30-31, nº 4; RAmírez SÁBADA 2003, 279, fig. 5).

44 La inscripción alude a la porta del monasterio: “+ (Alfa, Chrismon, Omega) Feliz Eugenia, sierva de Cristo, construyó una nueva puerta a la entrada (del cielo). Este es el claustro cuya dedicación encierra los votos de piadosas vírgenes. Patente quedará lo íntimo del Santuario a la veneración de todos los fieles. Atrios del Señor son estos que la virgen (Eugenia) madre de vírgenes, llevó a cumplida perfección, habiéndolos consagrado el pontífice Horoncio en el año 651" (SASTRE 2010, 18, fig. 2).

45 Lopes 2004, 155, fig. 106. 
asemejan a este tipo de crismones, como los documentados en la iglesia de Mosteiro (Concelho de Oleiros), datados en el año 616 d.C. ${ }^{46}$

De acuerdo con el análisis que hemos realizado anteriormente, podemos llegar a la conclusión de que el sillar de la tumba 593 se podría fechar en torno a los siglos VI-VII d.C. y quizá, preferentemente, en el siglo VII d.C., hipótesis amparada por los datos del contexto arqueológico del hallazgo en combinación con la documentación epigráfica y manuscrita conservada en Hispania.

La construcción de la tumba 593 supuso la reutilización del sillar, pues los cristogramas no eran visibles durante su uso como material de construcción del enterramiento (Fig. 7). Este reaprovechamiento del sillar nos invita a pensar que quizás, dada su cercanía a la entrada occidental del gran oecus o sala de representación, podría haber formado parte de una de las jambas de la puerta de dicho ambiente (Fig. 8). Poco se sabe sobre los cambios de función del área de representación de la villa a partir de la segunda mitad del siglo V d.C. No obstante, los escasos datos arqueológicos conservados permiten una aproximación a los procesos de abandono y amortización de estos espacios. Según las informaciones obtenidas en la excavación de la estancia M2, el oecus, pavimentado con un mosaico polícromo, se abandona en algún momento del siglo V d.C. y se inicia un proceso de desmantelamiento que implica el expolio de su tejado y de algunos sillares de arenisca que estructuraban la escalera de acceso y la entrada. El mosaico queda a la intemperie durante largo tiempo y sufre roturas y levantamientos, en parte provocados por la utilización del ambiente como zona residual de hábitat. ${ }^{47} \mathrm{La} \mathrm{habitación} \mathrm{queda} \mathrm{sellada} \mathrm{definitivamente} \mathrm{con} \mathrm{la} \mathrm{precipi-}$ tación de algunas vigas del tejado y el derrumbamiento de los paramentos que todavía se mantenían en pie. Todo este proceso, difícil de aquilatar cronológicamente, debió producirse entre los siglos $\mathrm{V}$ y VI d.C.

La estancia E 29, de algo más de $200 \mathrm{~m}^{2}$, debió de sufrir una alteración similar al del ambiente M2 o sala del mosaico. En esta habitación E 29, la secuencia arqueológica aparece mutilada y muy alterada. No se conservaban restos del pavimento original, el muro oriental que define la estancia se encontraba en su mayor parte expoliado y la secuencia estratigráfica se hallaba afectada, sobre todo en la mitad norte de la estancia, por continuas actuaciones llevadas a cabo sobre este espacio en época moderna y contemporánea. Aún así, se ha podido atestiguar el uso del espacio como cementerio en época altomedieval (siglos VIII al XI), ${ }^{48}$ así como la ubicación de las distintas tumbas con cierto interés por alcanzar una ordenación espacial en tres filas paralelas. De igual manera, el lugar tuvo una actividad sepulcral intensa ya que se han registrado varios niveles de enterramiento, superposición de tumbas y reutilizaciones. No hemos podido obtener información totalmente fidedigna sobre la función de E 29 entre los siglos VI y VII d.C. pero sabemos, por los datos obtenidos

46 Alves Dias - Sousa Gaspar 2006.

47 Se han identificado las huellas de hogares sencillos realizados sobre el pavimento musivario.

48 Se recogieron muestras de seis individuos procedentes de la estancia E 29 cuyas dataciones oscilan entre finales del siglo VIII e inicios del siglo XI d.C. T 479 (CNA 1373): 855-995, $95 \%$ a 2 б; T 429 (CNA 1370): 777-904, $95 \%$ a $2 \sigma$, T 429-1 (CNA 1371): 886-1157, $95 \%$ a $2 \sigma$; T 441 (CNA 1372): 773-900, $95 \%$ a 2 б; T 485 (CNA 1374): 778-900, $95 \%$ a $2 \sigma$; T 485-1 (CNA 1375): 805-996, $95 \%$ a $2 \sigma$ 


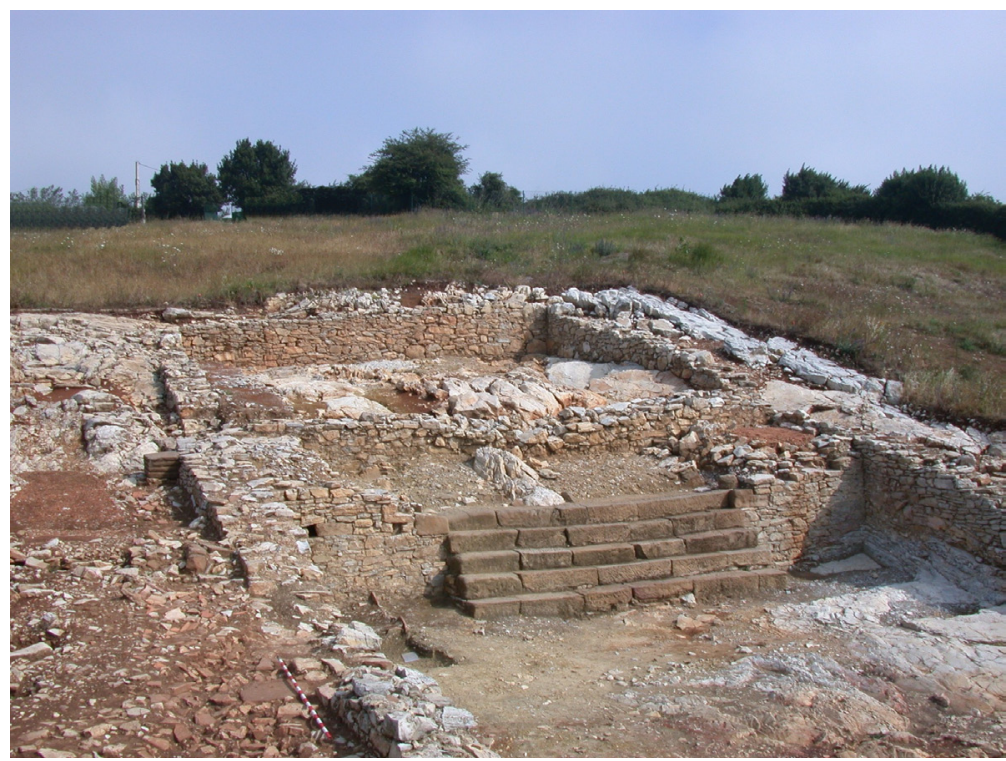

Fig. 8. Vista parcial del oecus de la villa (estancia E 29).

en otras zonas del yacimiento, que en estas fechas, este lugar debía formar parte de un complejo cristianizado (vid. infra). Este hecho podría explicar que los grafitos marcados en el sillar de la tumba 593 quizás estuvieron originariamente en una de las jambas de la entrada lateral de E 29 para señalar el acceso a un espacio vinculado con el lugar de culto, posiblemente a un coementerium.${ }^{49}$ El sentido de los crismones sería en este emplazamiento, por tanto, el de servir de protección de los fieles tanto en la vida como en la muerte, del mismo modo que se identifica el lugar como un espacio sagrado cristiano. Inscripciones con crismones realizadas en jambas de la entrada a espacios funerarios están perfectamente constatadas en la puerta de entrada al hipogeo de Dunes en Poitiers, ${ }^{50}$ ubicación que también pudo tener la placa con inscripción de época merovingia conservada en el Museo de Bagnères-de-Luchon. ${ }^{51}$ No parece que los crismones de Veranes formaran parte de los dinteles de un edificio cristiano, como se han documentado en otras regiones, sobre todo, en siglos posteriores. ${ }^{52}$

Dentro de este proceso de desmantelamiento y alteración profunda de las estructuras antiguas, se procedería a desmontar la antigua puerta occidental del oecus (E 29) y se reaprovecharían sus restos en las tumbas de las inmediaciones. En este momento

49 Entre la segunda mitad del siglo VI y los inicios del VII d.C. numerosos epígrafes aluden a los intentos de reconstrucción de los cementerios que generalmente se refieren a las tumbas individuales o cementerios colectivos situados junto a edificios basilicales de carácter funerario o martirial (DE SANCTIS 2010, 164-166).

50 Duval 1991, 228-229, fig. 3.

51 Colin 2008, 134-135, fig. 151.

52 Daugé 1916; Mesplé 1970; ID. 1972; Favreau et alii 1985; Garland 1988; ID. 1988a; Colin 2008, $138-141$. 
se produce la reutilización del sillar con los crismones grabados anteriormente que se incorpora a la estructura de la tumba 593. La disposición del sillar, que intencionadamente se coloca de modo que los crismones no sean visibles, nos indica que quienes construyen la tumba no parecen tener en cuenta el contenido simbólico de los cristogramas que porta el sillar. Múltiples podrían ser la causas que explican esa desatención al valor de dichos crismones, pero entre ellas podemos destacar la práctica generalizada del reaprovechamiento masivo del material constructivo detectado en toda esta área. Por el contrario, otras estructuras son respetadas y se mantienen en pie, como el antiguo triclinium, lugar que para entonces posiblemente se habría transformado en un complejo sacro. ${ }^{53}$

\subsection{El sillar de la Abadía de Cenero}

La iglesia o Abadía de San Juan Bautista de Cenero, próxima a las ruinas de Veranes, conserva en la entrada de la sacristía un gran sillar de arenisca con un grabado laciforme (Fig. 9). Esta pieza, junto con otros sillares y dovelas, fue encontrada formando parte de un acceso a la cuadra de una casa de la aldea de Veranes. La noticia procede de la obra del párroco de la abadía de Cenero, M. Valdés Gutiérrez, ${ }^{54}$ un erudito local que dedicó varios años de estudio a los restos hallados en Veranes y elaboró meritorios escritos sobre este yacimiento, sus orígenes, cronología e importancia en la Historia de Asturias. ${ }^{55}$ Para Valdés Gutiérrez, Veranes era un monasterio romano o visigodo, ${ }^{56}$ cuna del cristianismo astur, foco de resistencia frente al invasor islámico que lo destruye en el siglo VIII. Este autor es el primero en asociar las ruinas de Veranes con las citas medievales del Liber Testamentorum e identifica los restos arqueológicos como pertenecientes a la iglesia de San Pedro y Santa María de Riera. ${ }^{57}$ También realizó valiosas descripciones de los restos arqueológicos a principios del siglo XX, aportando así una apreciable documentación sobre elementos arquitectónicos y decorativos que no han llegado hasta nosotros.

Cuando Valdés Gutiérrez ofrece la noticia sobre este sillar, advierte que la pieza, junto con los otros sillares de la puerta, procedía de la entrada a la iglesia de Veranes, ${ }^{58}$ identificada en la actualidad con el oecus/triclinium de la casa romana (estancia M1 de la villa romana). Este afamado erudito interpreta el signo como un crismón y en 1952 traslada la piedra a su posición actual en la abadía de Cenero. ${ }^{59}$ En el año 1955, Bouza Brey publica un estudio sobre el grabado y lo identifica con la representación esquemática de un antropomorfo femenino muy estilizado elaborado sobre un ortoestrato

53 Fernández OchoA - Gil Sendino 2008, 446-448.

54 VALdÉs GutiérRez 1922, reed. 2005, 24.

55 FERnÁNDez OCHOA et alii 1998, 257-259.

56 La presencia de elementos claramente romanos le llevó a ajustar el origen de la construcción en el siglo III d.C.

57 FERnÁndez OchoA et alii 1998, 256.

58 VALDÉs GutiÉRrez 1922, reed. 2005, 24.

59 VALDÉs GutiérRez 1922, reed. 2005, 106. 


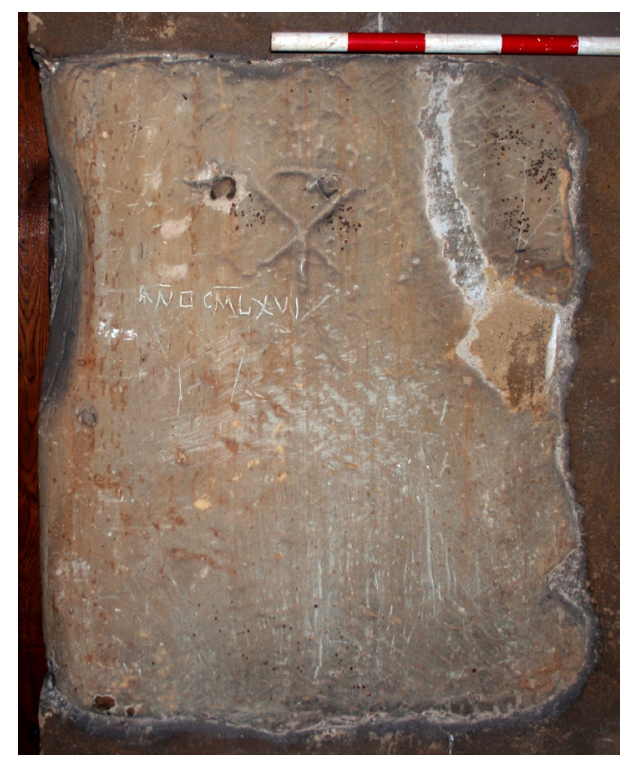

Fig. 9. Sillar del crismón de la Abadía de San Juan de Cenero (Gijón, Asturias).

megalítico ${ }^{60}$ y así lo citarán otros autores posteriores al tratar la prehistoria del concejo de Gijón. ${ }^{61}$

El grabado se encuentra inciso sobre un sillar de 0,90 $\mathrm{m}$ de altura, 0,76 $\mathrm{m}$ de ancho y $0,16 \mathrm{~m}$ de profundidad que sin duda formó originariamente parte de una jamba perteneciente a una puerta. La incisión configura un elemento de aspecto laciforme compuesto por una forma elipsoidal de la que parten de su extremo inferior tres vértices o líneas, el central vertical a modo de eje flanqueado por los otros dos oblicuos. El grabado tiene una altura de $0,17 \mathrm{~m}$ con una anchura de $0,12 \mathrm{~m}$. La representación del "sillar de la Abadía" mantiene características gráficas y de ejecución muy similares a los cristogramas aparecidos en el sillar hallado durante la excavación de Veranes (vid. supra). Posiblemente, y tal como apuntó en su día Valdés Gutiérrez, el dibujo de Cenero corresponde también con una cruz monogramática con las letras X (chi) y $\mathrm{P}$ (rho) intercaladas verticalmente, determinando una posición simétrica de dos aspas oblicuas de la chi, mientras que la rho permanece como eje de las otras dos aspas de la cruz (Fig. 10). En este sentido, conviene recordar la existencia de otros laciformes y antropomorfos encontrados en Asturias e interpretados en su día como petroglifos de la Edad del Bronce. El valor simbólico de estos signos ha sido cuestionado en los últimos años por varios autores. ${ }^{62}$ Algunos de estos grabados se pueden identificar como grafitos realizados en épocas históricas que tendrían un claro simbolismo religioso de carácter cristiano. Es el caso del grafito de la Xorenga en Grandas de Salime

60 Bouza Brey 1955, 355.

61 GonzÁlez 1979, 19-20.

62 Gutiérrez GonZález 1999; Villa Valdés 2000. 


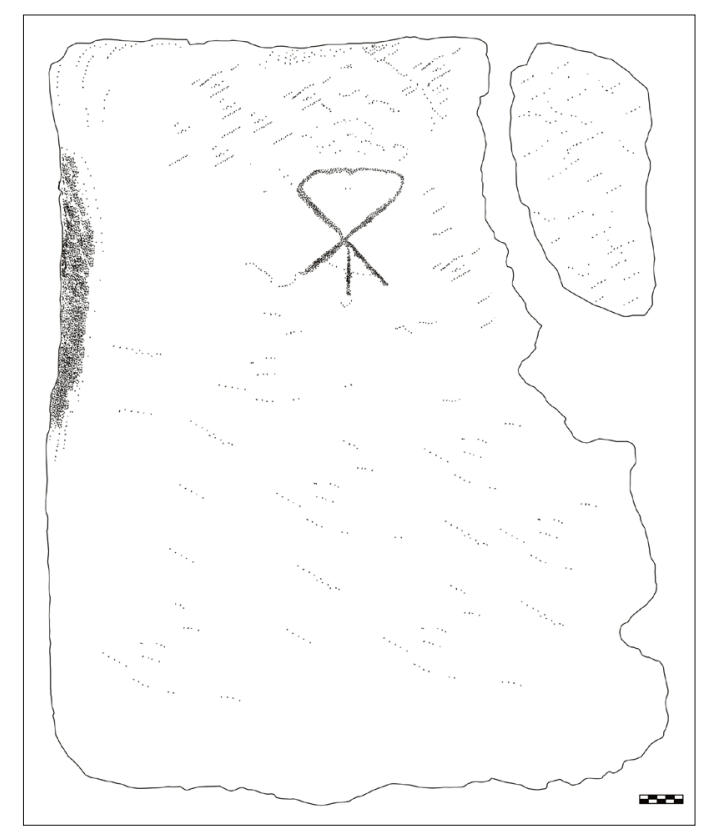

Fig. 10. Dibujo del sillar con crismón de la Abadía de San Juan de Cenero.

o de los petroglifos de La Pendilla (León), de trazados muy parecidos al hallado en Cenero.

Así pues, el grabado del sillar de la Abadía de Cenero puede constituir un cristograma de tipo constantiniano que presenta una apariencia muy esquemática debido a la técnica empleada en su ejecución, concretamente el grabado, un simplismo que encontramos también en grafitos del siglo IV d.C. como el documentado en el cierre de uno de los enterramientos de la catacumba de San Sebastián en Roma (Fig. 11a). ${ }^{63}$

Apenas se han documentado crismones de estas características, aunque el repertorio de estos símbolos es amplio y muy variado. Algunas representaciones muestran una cierta semejanza al crismón analizado, no tanto por su ejecución -poco cuidada en el caso del crismón de la Abadía de Cenero-, sino por la disposición de los elementos que configuran el cristograma. Se han localizado algunos crismones de época romana, como el realizado en un ladrillo procedente de Estepa (Sevilla), que guardan cierta similitud con el de Veranes (Fig. 11b). ${ }^{64}$ Al igual que el crismón asturiano, presenta dos aspas diagonales superiores sin travesaño, que son más redondeadas en el caso del crismón de la Abadía, y la xi que constituye el cuerpo del símbolo. El crismón bético, en cambio, cuenta con una rho en el interior de la xi y la omega que, en forma de yugo, sirve de base del emblema. El simbolismo cristológico del ladrillo

63 YAMADA 1999, 295-296, fig. 11.

64 Recio Veganzones 1978, fig. 18. 


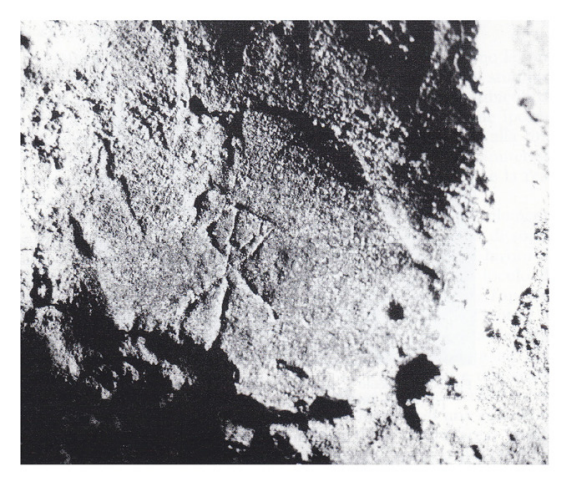

a

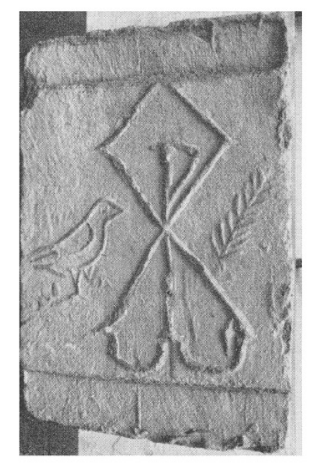

b

Fig. 11. a- Cristograma grafitado de la Catacumba de San Sebastián en Roma, según YAMADA (1999, 295-296, fig. 11); b- Ladrillo con representación de crismón aparecido en la Bética, según Recio Veganzones (1979, 71, fig. 18).

bético se ve, además, corroborado por la presencia de un tema netamente sepulcral o funerario, es decir, la paloma y el ramo o palma.

\section{Veranes y la implantación del cristianismo en Asturias}

Procedentes de diversos contextos se pueden reseñar otros materiales hallados en Asturias que contienen cristogramas o crismones cuya cronología antecede o coincide con la fecha que otorgamos a las piezas de Veranes. No hace falta recordar el magnífico crismón esculpido en la tapa del sarcófago de Itacio, pieza conocida desde el siglo XVI y conservada en la Capilla de Santa María o del rey Casto en la Catedral de Oviedo. El exhaustivo estudio realizado por Vidal Álvarez ${ }^{65}$ sobre este motivo nos exime de incidir sobre sus peculiaridades y simbología, así como su cronología que se propone a partir de finales del siglo V d.C. o en el siglo VI d.C. ${ }^{66}$

Otra pieza excepcional con crismones impresos en su interior es la fuente de $T e$ rra sigillata africana $D$ hallada en las excavaciones de la muralla de Gijón. También en este caso se trata de un ejemplar ampliamente estudiado en su día ${ }^{67}$ y cuya procedencia del alfar de El-Marine, en Cartago, permite asegurar una cronología de fabricación entre los años 460-480 d.C. ${ }^{68}$ La cuestión que suscita esta cerámica es su relación con el culto cristiano como tal. No resulta fácil saber la utilización de esta

\footnotetext{
65 Vidal Álvarez 2005, 88.

66 Este investigador está realizando en la actualidad nuevos estudios sobre esta pieza centrados en los análisis arqueométricos del mármol.

67 Alonso - Fernández Ochoa 1988; Fernández Ochoa 1997, 95.

68 Fernández OchoA et alii 1992, 114-115.
} 


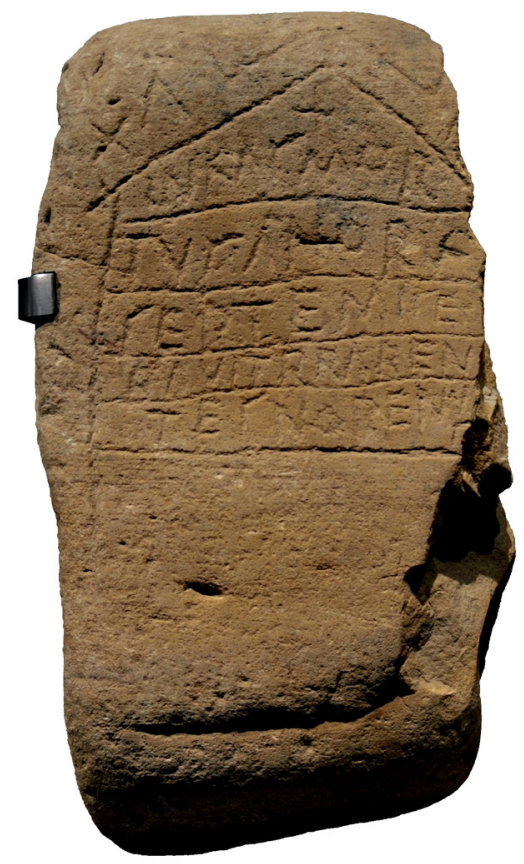

Fig. 12. Estela de Norenus depositada en el Museo Arqueológico de Asturias.

pieza, es decir, si se trata de un ejemplar destinado al uso como vajilla de mesa dentro de un cargamento con materiales diversos, como era habitual en los circuitos comerciales tardoantiguos, o bien si debemos concederle un sentido simbólico cristiano quizá litúrgico, que posiblemente tenía en el contexto de su fabricación. Ya en su día señalamos el posible valor emblemático cristiano de la pieza ${ }^{69}$ que sería adquirida por un comprador que apreciaba y comprendía el motivo impreso en esta gran fuente de cerámica procedente de la actual región tunecina.

Por último, hemos de señalar la presencia de un crismón en la estela de Norenus hallada en Soto de Cangas de Onís. ${ }^{70} \mathrm{El}$ monograma aparece insertado bajo el vértice del frontón que envuelve el texto y se reconoce perfectamente el trazo curvo de la $\mathrm{P}$ (rho) (Fig. 12). La mayoría de los autores consideran este signo como cruz o esvástica simplificada, ${ }^{71}$ a excepción de Navascués que, desde el principio, lo interpretó como un crismón. ${ }^{72}$ Hemos podido confirmar este dato con motivo del traslado de

69 Alonso - Fernández OchoA 1988, 368.

70 El texto es como sigue: In memoriam sanctam. Mor/tuus annorum / septem mise/ravit relictos paren/ tes Norenu/s (En el nombre de Cristo, dedicado a su santa memoria. Noreno murió de siete años, dejando a sus padres en la tristeza) en ERA 44 (CIL II, 5745; EC 116).

71 Fernández Guerra 1878, 133-134; Diego Santos 1959, 123-125; Iglesias 1976, 92; Rodríguez Colmenero 1987, 179; Calleja 2005.

72 NAVASCUÉs 1972, 160. 
los epígrafes romanos a la nueva sede del Museo Arqueológico de Asturias en el año 2010. No cabe duda de que la estela porta este símbolo cristiano. No obstante, su datación es imprecisa y se sitúa entre fines del siglo IV y el siglo V d.C. ${ }^{73}$

La importancia de los crismones hallados en Veranes, cuya datación proponemos entre los siglos VI y VII d.C., debe apreciarse en el marco del exiguo elenco de documentos materiales disponibles sobre las etapas iniciales del cristianismo en Asturias. La primera evidencia de Cristianismo en el solar asturiano se corresponde con el epígrafe de Argüero $(H E p$ 7, 1997, 20), fechado a finales del siglo III o durante la primera mitad del siglo IV d.C., ${ }^{74}$ que implica la construcción de un lugar de culto cristiano en la zona central de Asturias en fechas muy tempranas. La piedra, que debió formar parte del dintel de una puerta o ventana, se encontró en el barrio de San Feliz, nombre que De Francisco ${ }^{75}$ asocia al de Félix, el Africano, mártir de Gerona durante las persecuciones de Diocleciano, cuyo recuerdo estuvo muy presente durante los siglos IV y V d.C. En consecuencia, fueron los núcleos urbanos del área central de Asturias los primeros focos cristianos y desde estos centros se captaron los nuevos adeptos. Para el siglo VI d.C. contamos con nuevos testimonios sobre lugares de culto en el área central de Asturias. La inscripción de San Martín de Argüelles confirma la construcción de una iglesia hacia el 583 d.C. De la zona vadiniense proceden dos inscripciones funerarias, la ya citada de Norenus y la conocida como de Magnentia ${ }^{76}$ clasificadas como cristianas y fechadas entre la segunda mitad del siglo IV y la primera mitad del siglo $\mathrm{V}$ d.C.

Durante los siglos V y VI d.C., la zona occidental de Asturias permaneció bajo la influencia, más o menos efectiva, del reino suevo de la Gallaecia. El Parroquial Suevo fechado hacia los años 579-580 d.C., ordenado redactar por el rey Teodomiro, incluye el término Pesicos, única parroquia de los astures transmontanos dependiente de la sede episcopal de Astorga. Esta parroquia debemos identificarla con el antiguo pueblo de los pésicos de época romana, cuyo territorio se extendía entre los ríos Nalón y Navia. ${ }^{77}$ En los documentos medievales de los siglos X y XI d.C. todavía se mantiene esta denominación para referirse a las tierras situadas en torno a la cuenca baja del Nalón y su afluente el río Narcea, donde el rey Silo había trasladado la sede del joven reino astur. Tanto las comunidades vadiniense como la pésica, con una larga tradición cristiana en el siglo VIII d.C., contribuyeron a fortalecer el novedoso proyecto de gobierno basado, según las fuentes, en la ideología cristiana como filosofía

\footnotetext{
73 Algún autor propone que la decoración en la estela de Magnentia (DiEGo SANTos 1985, n. ${ }^{\circ} 45$ ), también considerada cristiana, podría contener criptogramas (RodRíGuez ColmENERo 1987). La observación directa de la pieza ofrece dudas acerca de esta interpretación ya que podría tratarse simplemente de los trazos que conforman los remates de una decoración de tendencia oikomorfa.

74 Esta temprana cronología ha sido, sin embargo, puesta en duda por Isabel Velázquez $(H E p ~ 7,1997,20)$.

75 Decus / egit / Chri(stus) dius (Cristo Dios, autor de todo lo bello; De Francisco 1997, 22).

76 Magnen/tia excedit / annoru(m) v/i(gi)nti (dierum) XXV/ ex domu d/ominica (ERA 45; EC 117; HAE 1673; HEp 2, 1990, 26). La decoración de la estela incluye elementos que parecen recordar a la $x i \mathrm{y}$ rho, abreviaturas de Cristo, aunque todavía existen serias dudas sobre la significación cristiana de dichos signos (HEp 2, 1990, 26).

77 Besga Marroquín 2010, 922-923.
} 
política. ${ }^{78}$ Otra referencia del parroquial suevo permite, según Fernández Conde, ${ }^{79}$ apreciar el papel del monacato en la cristianización de Asturias durante los siglos VI y VII d.C. El documento suevo menciona la sede de Britonia, el monasterio de Máximo y "las iglesias que están en Asturias". Para Fernández Conde, ${ }^{80}$ "las iglesias" citadas por el documento suevo se corresponderían a los lugares de culto situados al este de la parroquia de los pésicos, cuyo cristianismo estaría vinculado a una organización de tipo monástico. ${ }^{81}$ A partir de mediados del siglo VI d.C., la presencia del mundo visigodo se hace cada vez más patente en la Asturia Transmontana. A principios del siglo VII d.C. el reino visigodo acuña en Pesicos. Las emisiones estaban relacionadas con las campañas militares encaminadas a implantar un control efectivo sobre estas tierras. Varios canceles visigodos hallados en la zona central de Asturias se corresponden con iglesias del siglo VII d.C. levantadas por la monarquía visigoda, fruto de su política de dominio y control en la región. Asimismo, alguno de los jarros litúrgicos quizá tuvo el mismo origen. A estos elementos muebles de la liturgia cristiana también se los considera consecuencia de las labores de evangelización de monjes en los siglos VII y VIII d.C., e incluso resultado de migraciones mozárabes tras la conquista islámica. ${ }^{82}$

El sillar de la tumba 593 de Veranes, a pesar de su traza elemental y de la ausencia de aspectos decorativos, adquiere un especial valor por su exhumación en un contexto arqueológico controlado que nos ha permitido conocer de primera mano su ubicación, los detalles de su presencia sobre las ruinas de la antigua villa romana y, consecuentemente, su probable cronología. En cuanto al sillar de la Abadía, no tendría nada de extraño que en su labra y primera reutilización hubieran concurrido unas circunstancias semejantes. Estas piezas con símbolos cristianos proceden de un enclave rural de la máxima importancia en época romana que permanecerá ocupado a lo largo del tiempo. Este fenómeno de progresiva cristianización del espacio ocupado por la antigua villa de Veranes se inserta dentro del panorama general que afectó al Occidente del Imperio. Desde la segunda mitad del siglo IV d.C., la promulgación del Edicto de Tesalónica del año 380 d.C., por iniciativa de Teodosio, impone oficialmente la religión cristiana a todos los ciudadanos del Imperio. Es posible que los latifundistas convertidos al cristianismo trasladaran hasta sus posesiones la nueva corriente religiosa, lo que supondría la construcción de iglesias rurales ya desde tiempos tan remotos como los comienzos del siglo V d.C. ${ }^{83}$ pero la documentación arqueológica

78 FERnÁndez CONDE 2002, 280.

79 FERnÁndez CONDE 2002.

80 Fernández Conde 1972; Fernández Conde 2000; Fernández Conde 2002.

81 El debate sobre la sede britona y su territorio ha sido tratado ampliamente, entre otros, por P. David y L. García Moreno. Vid. Besga Marroquín 2010, 93-94.

82 Una síntesis general se puede consultar en CALLEJA 2005.

83 Como señala CHAVARRía $(2006,205)$, una buena prueba de estas acciones es la mención de la construcción de iglesias en villae, según se recoge en el canon 5 del I Concilio de Toledo, datado en torno al año 400 d.C., en el que se amonesta a los clérigos que no acuden a la misa en residencias rurales privadas reconocidas por la iglesia, in loco in quo est ecclesia aut castelli aut vicus aut villae. 
ofrece evidencias de construcción de iglesias rurales en Hispania solamente a partir del siglo VI d.C., cuando ya las villae han perdido su carácter residencial. ${ }^{84}$

Los indicios de ruina y progresivo abandono de la villa de Veranes coinciden con la aparición de las primeras inhumaciones descubiertas en algunas estancias de la zona señorial. En la estancia E 10 se localizó una tumba infantil (T 401), cuya fosa se abre en el pavimento de opus signinum de la habitación. El enterramiento se llevó a cabo en el interior de un gran recipiente cerámico tardorromano y los análisis realizados sobre los restos óseos conservados proporcionan una datación entre el 395 y el 564 d.C. $(94,3 \%$ a $2 \sigma){ }^{85}$ En la misma unidad estratigráfica, y rompiendo también el pavimento de la habitación, se encontró otra tumba infantil (T 125) confeccionada con dos ímbrices y orientada al Norte. ${ }^{86}$ Por otro lado, en el interior de la galería porticada (E 11) se identificó un enterramiento (T 312), cuya fecha radiocarbónica sitúa la deposición del muerto entre mediados del siglo VI y la segunda mitad del siglo VII d.C. (557-686, 93,5\% a $2 \sigma)$. ${ }^{87}$ Igualmente, en el interior de la estancia E 17 se ha analizado un enterramiento (T 106), ${ }^{88}$ orientado en sentido Norte-Sur, que debió inhumarse durante la segunda mitad del siglo VII o inicios del siglo VIII d.C. Durante el proceso de excavación arqueológica esta tumba se localizó bajo una estructura de reducción metalúrgica en funcionamiento en algún momento entre la segunda mitad del siglo VII y el siglo VIII d.C. Sobre este primer nivel de necrópolis se registra un nuevo estrato cementerial de tumbas de lajas. La presencia de estos enterramientos de fecha tardoantigua parece coincidir cronológicamente con la data de los materiales asociados a la etapa de abandono de la zona de la puerta ${ }^{89}$ y con el fin del uso de un basurero situado extramuros, junto al acceso principal de la villa. ${ }^{90}$ Estas inhumaciones pueden considerarse señales del proceso de transformación de la villa, quizá asociadas a un cambio en la propiedad del fundus pero, en todo caso, su presencia indica el comienzo de una discontinuidad en las funciones del espacio. Las escalas precisas de estas transformaciones deben vincularse a fenómenos de evolución en los sistemas de poder y fiscalidad dentro del ámbito rural que repercutió en la organización de las tierras y propiedades y, en definitiva, en la modalidad de explotación del territorio. En el mismo sentido se inscriben los restos de las actividades metalúrgicas de transformación del hierro documentadas en Veranes sobre las ruinas de la cocina (E 28; $637-709,90 \%$ a $2 \sigma)^{91}$ y la $\operatorname{diaeta}(\mathrm{E} 17 ; 642-720,84,9 \%$ a $2 \sigma),{ }^{92}$ cuya cronología se ha podido fijar en torno al siglo VII d.C.

84 ChavarRía 2007, 143 y ss.

85 Ua-20550.

86 En este caso desgraciadamente no se conservaban restos humanos.

87 Ua-21459.

88 660-775 d.C. (95,4 \% a 2 б); Ua-18098 y Ua-20552.

89 FernÁndez OCHOA et alii 2007.

90 En este contexto se recuperaron, entre otros materiales, varios fragmentos de TSHT 37 decorada con círculos secantes, TSA, TSGGT, instrumentos agrícolas de hierro de típica tipología tardorromana y varios ejemplares de cuchillos tipo Simancas.

91 CSIC-2007.

92 CSIC-1722. 


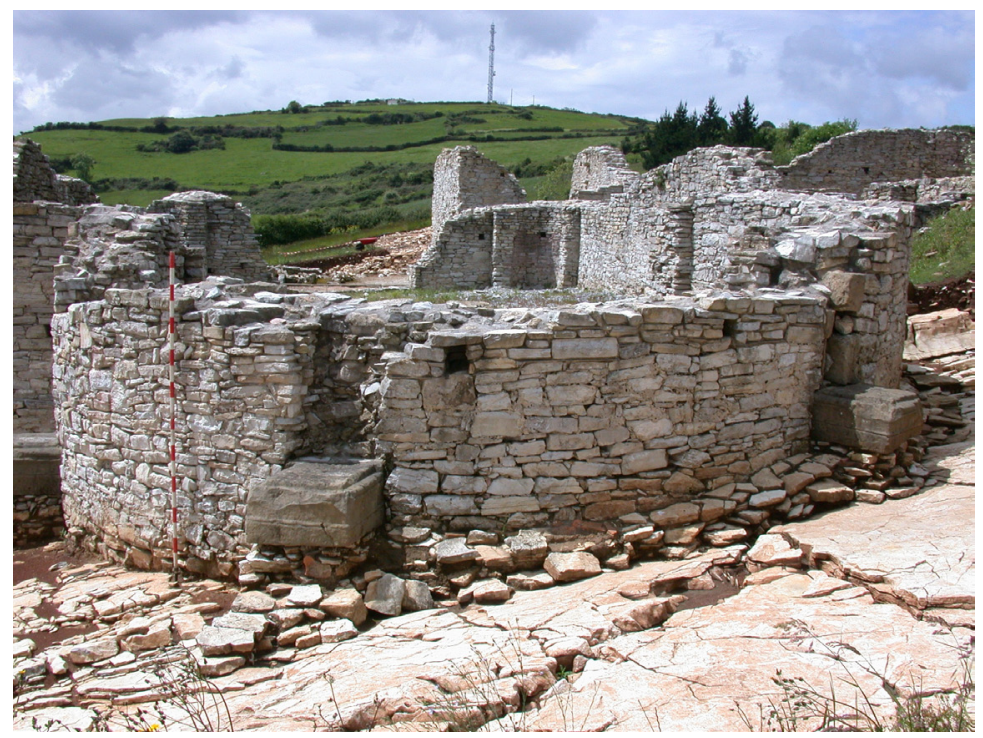

Fig. 13. Estado actual del triclinium de la villa romana de Veranes que se convertirá en iglesia de Santa María y San Pedro.

La existencia de estas primeras inhumaciones parece responder a la conversión del área meridional de la villa en lugar de culto en torno a una primitiva iglesia que ocuparía el espacio del antiguo triclinium (M 1) y las habitaciones adyacentes (Fig. 13). No ha sido posible detectar hasta el momento, con datos arqueológicos seguros, el grado de conexión entre los enterramientos tardoantiguos y el centro de culto instalado en el antiguo triclinium, aunque contamos con algunos argumentos que avalan, como hipótesis de trabajo, la conexión entre ambas realidades históricas. La excavación arqueológica ha demostrado que las estructuras de la pars urbana se abandonan y amortizan durante la segunda mitad del siglo V o inicios del siglo VI d.C., excepto el triclinium (M 1) y las estancias próximas a éste. Estos espacios permanecen en pie a lo largo del tiempo y en el siglo IX d.C. sabemos que están siendo utilizados como iglesia de la aldea o lugar de Riera bajo la advocación de San Pedro y Santa María. ${ }^{93}$ Los paramentos del triclinium conservan en la actualidad alzados que alcanzan los 4 $m$ de la fábrica original romana y existen fotografías de Veranes de inicios del siglo $\mathrm{XX}$ en las que se aprecia cómo estos muros superaban los 8 metros de altura. Resulta poco probable que estas estancias permanezcan en pie abandonadas desde el siglo VI d.C. hasta el VIII o IX d.C. sin que se arruinen y sean expoliadas. Sólo la utilización continuada de los ambientes mencionados justifica su conservación a lo largo del tiempo. Además, no hay evidencias de reconstrucciones o edificaciones de nueva planta relacionadas con la iglesia altomedieval. El culto se practicó en el aula romana hasta su abandono definitivo en los albores de la Baja Edad Media. Por otro lado, los

93 García Larragueta 1962, doc. nº 17; Fernández Ochoa et alii 1997. 
nombres de San Pedro y Santa María forman parte de las advocaciones asociadas, en la arqueología de época cristiana, a fundaciones antiguas y conversiones de espacios paganos en nuevos centros cristianos. Junto a ello, es muy frecuente que los rituales cristianos se desarrollen en los grandes frigidaria de las áreas termales de las villae o en las grandes estancias de representación. Estos hechos se dan conjuntamente o por separado en muchas iglesias o lugares de culto más antiguos. En cuanto a la denominación hagiotoponímica que presenta la iglesia de Veranes, el paralelo más cercano, entre los muchos existentes, ${ }^{94}$ es el de Santa María de Lugo de Llanera, que aparece mencionada en el Liber Testamentorum y que las autoras de las excavaciones arqueológicas desarrolladas en el antiguo solar de época romana señalan como un índice de su antigüedad. ${ }^{95}$ También presenta esta advocación primitiva la iglesia de San Pedro, de Gijón, centro cultual cristiano construido al menos en el siglo VII d.C. en el mismo lugar que antes habían ocupado las termas públicas de la ciudad romana y rodeado de una necrópolis tardoantigua y medieval. ${ }^{96}$

Por último, en la documentación medieval de finales del siglo X y principios del siglo XI d.C. ${ }^{97}$ se recoge el término Berani utilizado para identificar un amplio territorio que incluye el lugar de Riera y la iglesia de San Pedro y Santa María. El fundus de Veranius mantendría entonces, a grandes rasgos, su unidad espacial que quedaría fosilizada a partir del siglo XIII d.C., en el territorio parroquial de Cenero. Esta evolución se puede explicar desde la transmisión de las tierras en la Tardía Antigüedad a un nuevo possesor que convierte una amplia estancia de la pars urbana en centro de culto cristiano. Así, la imagen y el lugar de representación del nuevo señor mantendrían, ante las gentes del lugar, la misma carga simbólica de poder y dominio del periodo tardorromano. La presencia creciente de la Iglesia en el ámbito rural contribuyó de manera definitiva a la crisis de la vieja aristocracia y a la emergencia de nuevas élites poderosas vinculadas a la nueva religión $\mathrm{y}$, sin duda, a nuevos ambientes militares tras la definitiva retracción del Estado romano. El papel centralizador del territorio detentado por el enclave tardorromano de Veranes permanecería pero, en manos de un nuevo poder de signo religioso.

A partir del siglo VIII d.C., las clases dirigentes utilizaron nuevas formas de dominio señorial, como las fundaciones monásticas y los castillos. La villa de Veranes se mantuvo como lugar de culto en tanto que la zona montañosa y boscosa del fundus fue controlada mediante la construcción de una fortificación encaramada en lo alto de un cerro. Allí, en la cima de un alto llamado Picu Alba, destacado sobre los valles circundantes, se instaló en la Edad Media el castillo de Curiel, mencionado en varios documentos escritos de los siglos XII y XIII d.C. ${ }^{98}$

94 Jimeno Aranguren 2006, 244.

95 Fernández Ochoa et alii 2001, 135.

96 Véase Fernández OchoA - García Díaz 1996; Peña Cervantes 2000, 351. Procedentes de la necrópolis asociada a la antigua iglesia de San Pedro se dataron dos tumbas halladas en la Plaza del Arcipreste Piquero. Los resultados de los análisis radiocarbónicos, inéditos hasta la fecha, han permitido situar el momento de inhumación de dichos enterramientos a finales del siglo VII y durante el siglo VIII d.C. T 3: Ua-32246, 670$890,95 \%$ a 2 б; T 4: Ua-32247, 680-900, 95,4\% a 2 .

97 Floriano Llorente 1968, n⿳0 26.

98 Gutiérrez GonZÁlez 2003. 
Por otra parte, se han localizado diferentes elementos arqueológicos que transmiten indicios sobre las formas de vida de las gentes de los entornos de Veranes durante la Edad Media. En el Patio Norte se han documentado restos de estructuras lígneas asociadas a espacios de hábitats medievales, hecho cada vez mejor documentado en yacimientos medievales excavados en los últimos años. ${ }^{99}$ En Veranes, estos elementos son los negativos de fosas de postes y los restos excavados en el sustrato geológico de una cabaña de tendencia circular con hogar central fabricada con madera y arcilla. La vivienda carecía de tabiques o distribución interior y cumplía las funciones de cocina, sala y dormitorio. Otro testimonio de hábitat medieval se ha constatado en la estancia E 12, donde se pudo identificar un espacio fechado en el siglo X d.C. ${ }^{100}$ que reutilizaba los muros de la antigua villa y en cuyo suelo se recuperaron un hogar, un molino y abundantes bellotas. También, como ya hemos apuntado más arriba, se han encontrado tres cubetas de reducción metalúrgica aprovechando los muros arruinados de la villa romana. Dos se localizan en la estancia E 17 (antiguo cubiculum principal), y una tercera, junto al paramento occidental de la cocina (E 28).

La verificación de las estructuras de hábitat y la presencia de actividad siderúrgica en una zona relacionada con espacios cultuales induce a reflexionar sobre las gentes que habitaban el lugar, realizaban los trabajos y controlaban el producto final, ${ }^{101}$ e incide sobre la titularidad del centro de culto como parroquia o monasterio. Las fuentes medievales son muy parcas en información sobre la iglesia de Veranes y su régimen eclesial y poca luz aportan para esclarecer estos términos. Resulta sugerente relacionar el lugar de culto y la industria siderúrgica a la hora de esbozar la hipótesis de un asentamiento monacal en la Alta Edad Media en Veranes que regentaría el lugar consagrado y explotaría los recursos metalúrgicos ahora descubiertos. Sin embargo, el terco silencio de las fuentes documentales parece subrayar la teoría de una explotación llevada a cabo por una comunidad independiente, de poblamiento diseminado, vinculada a un territorio conocido como Riera, que tiene su lugar de referencia comunal en torno al centro cultual y que sólo perderá el control sobre la producción siderúrgica en momentos avanzados de la Edad Media, consecuencia de la presión que los señores laicos y eclesiásticos irán ejerciendo sobre estos núcleos de gentes libres.

A pesar del proceso de fragmentación espacial de la villa de Veranes, la secuencia ocupacional continúa hasta el siglo XIV. Los materiales cerámicos asociados a los suelos de uso de la necrópolis ${ }^{102} \mathrm{y}$ la recuperación de más de treinta monedas emitidas en el siglo XIII y primera mitad del siglo XIV d.C., vinculadas al último momento de las inhumaciones y a la amortización del cementerio, sugieren el final de la ocupación a lo largo del siglo XIV.

99 AzKarate - Quirós 2001.

100 Del suelo de uso medieval (UE 1074) se han obtenido dos dataciones radiocarbónicas sobre bellotas (CSIC-1598, 804-982, 90,07 \% a $2 \sigma$ ) y madera (CSIC-1650, 932-1004, 60,8 \%, a 2 \%).

101 Gutiérrez GonZÁlez et alii 1999, 23-24.

102 La necrópolis medieval de Veranes se encuentra en fase de estudio. Se puede consultar una síntesis en Fernández OchoA - Gil Sendino 2007; Fernández OchoA - Gil Sendino 2007b; Fernández OchoA - Gil Sendino 2009. Los análisis antropológicos de la necrópolis de Veranes se realizan bajo la dirección de los profesores Armando González y Josefina Rascón (Departamento de Antropología de la UAM). 
La información transmitida por el libro becerro confirma cómo a finales del siglo XIV d.C., el templo de Veranes ya no funcionaba como centro parroquial y sus funciones habían sido trasladadas a la Abadía de San Juan Bautista de Cenero, construida posiblemente en el siglo XIII. La abadía aglutinaba entonces los núcleos de San Pedro y Santa María de Riera y San Juan de Lleme, así como las villas de Caravedo, Sotiello y Coto. ${ }^{103}$ La nueva ordenación de los valles tendía a centralizar las feligresías, con lo que se conseguía un control más efectivo de sus pobladores, se organizaban los recursos productivos y se optimizaba el sistema fiscal. ${ }^{104}$

Se podría afirmar que la villa romana de Veranes, al igual que otras villae hispanas, se convirtió, desde finales del Imperio, en un foco de cristianismo adoptando un modelo bien conocido donde se dan cita la iglesia, el cementerio y otra serie de actividades relacionadas con el mantenimiento de su importancia como centro de carácter rural, quizá acorde todavía con el papel que anteriormente había ostentado la villa romana en esos mismos territorios.

Durante la Tardía Antigüedad, la Asturia Transmontana continuó su proceso de cristianización desarrollado por monjes y eremitas, pero también incentivado por los poderes políticos suevos y visigodos. En el siglo VIII d.C., la población de estas tierras hacía tiempo que vivía en un ambiente socio-político y cultural cristiano.

\section{Bibliografía}

Alonso, M. A. - Fernández OchoA, C. (1988): "Cerámica africana D con decoración paleocristiana en la muralla de Gijón", CuPAUAM 15, 339-377.

Alves Dias, M. M. - Sousa Gaspar, C. I. (2006): Catálogo das Inscrições Paleocristãs do Território Português, Lisboa.

Arce, J. - Brogiolo, G. P - Chavarría, A. (eds.), (2006): Villas tardoantiguas en el Mediterráneo Occidental (=Anejos de AEspA XXXIX), Madrid.

Azkarate, A. (1988): Arqueología Cristiana en la Antigüedad Tardía en Álava, Guipúzcoa y Vizcaya, Vitoria-Gasteiz.

Azkarate, A. - Quirós, J. A. (2001): “Arquitectura doméstica Altomedieval en la península ibérica. Reflexiones a partir de las excavaciones arqueológicas de la catedral de Santa María de Vitoria-Gasteiz (País Vasco)", Archeologia Medievale XXVIII, 25-60.

Baudry, G.-H. (2009): Les symboles du christianisme ancien: Ier-VIIe siècle, Paris.

Beltrán De Heredia, J. (2010): "La cristianización del suburbium de Barcino", [en] D. Vaquerizo (ed.), Las áreas suburbanas en la Ciudad Histórica. Topografía, usos, función, Córdoba, 363-395.

Bernal Casasola, D. (2008): "Ciudades del «Fretum Gaditanum» tardoantiguo: pesquerías y comercio transmediterráneo en época bizantina y visigoda", Zona arqueológica 9, 363383.

103 García Álvarez-Busto 2006, 150.

104 Vid. Fernández OchoA et alii 2012. 
Besga Marroquín, A.

(2000): Orígenes hispanogodos del reino de Asturias, Oviedo.

(2010): "La Asturias de los astures durante los siglos V-VII según las fuentes literarias", [en] J. I. Ruíz de la Peña - J. Camino (coords.), La Carisa y La Mesa. Causas políticas y militares del origen del Reino de Asturias, Oviedo, 85-127.

Bouza Brey, F. (1955): "El grabado rupestre antropomorfo de Veranes", Boletín del Real Instituto de Estudios Asturianos 9/26, 345-355.

Brogiolo, G. P.

(1997): La fine delle ville romane: tranformazioni nelle campagne tra tarda antichittá y alto medievo, Roma.

(2006): "La fine delle ville: dieci anni dopo", [en] Chavarría - Arce - Brogiolo (eds.), 2006, Madrid, 253-273.

Brogiolo, G. P. - ChavarríA, A. (2005): Aristocrazie e champagne nell'occidente da Costantino a Carlomagno, Firenze.

Brogiolo, G. P. - Chavarría, A. - Valenti, M. (eds.), (2005): Dopo la fine delle ville: evoluzione nelle champagne dal VI al IX seculo, Mantova.

Bruun, P. (1966): The Roman Imperial Coinage VII, Constantine and Licinius, London.

BüCHELER, F. (1895-1926): Carmina Latina Epigraphica I-III, Leipzig (=CLE).

Calleja Puerta, M. (2005): "La Asturias Medieval”, [en] A. Fernández Pérez - F. Riera Suárez (coords.), Historia de Asturias, Oviedo, 175-181.

CAlvo, M. (2000): “El cementerio del área episcopal de Valencia en la época visigoda”, [en] A. Ribera (coord.), Los orígenes del Cristianismo en Valencia y su entorno, Valencia, 193205.

CAmpione, A. (2000): La Basilicata paleocristiana. Diocesi e culti, Bari.

CARletti, C. (2008): Epigrafia dei Cristiani in Occidente dal III al VII secolo: ideologia e prassi (=Inscriptiones Christianae Italiae. Subsidia 6), Bari.

Carvalho, A. (1994): “A villa romana da Quinta das Longas (S. Vicente e Ventosa, Elvas): as prospecções de 1990”, [en] Actas das V Jornadas Arqueológicas (Lisboa, 1993), Lisboa, vol. 2, 239-251.

Cavalcanti, E. (1996): "La diffusione del cristianesimo nei primi secoli”, [en] Donati (coord.), 1996, 17-43.

Cerrillo Martín de CÁceres, E. (1974): “Los relieves de época visigoda decorados con grandes crismones", Zephyrus 25, 439-455.

Chavarría Arnau, A.

(2004): "Considerazioni sulla la fine delle ville in Occidente", Archaeologia Medievale XXXI, 7-19.

(2006): “Aristocracias tardoantiguas y cristianización del territorio", Rivista di Archeologia Cristiana 82, 201-230.

(2007): El final de las villae en Hispania (siglos IV-VII d.C.), Turnhout.

Chavarría Arnau, A. - Arce, J. - Brogiolo, G.-P. (eds.), (2006): Villas tardoantiguas en el Mediterráneo Occidental (=Anejos de AEspA XXXIX), Madrid, 253-273.

Colafrancesco, P. - Massaro, M. (1986): Concordanze dei Carmina Latina Epigraphica, Bari. 
Colin, M.-G. (2008): Christianisation et peuplement des campagnes entre Garonne et Pyrénées, IVe-Xe siècles, Carcassonne.

Daugé, S. (1916): "Inventaire des chrismes du département du Gers, première serie", Bulletin de la Société Archéologique Historique et Littéraire du Gers 17/1-2, 58-72.

De Francisco, J. (1997): "Nueva inscripción paleocristiana de Argüero (Villaviciosa, Asturias)", Memorana 1, 19-24.

De Sanctis, P. (2010): Sanctorum monumenta: “aree sacre” del suburbio di Roma nella documentazione epigrafica (IV - VII secolo), (=Inscriptiones Christianae Italiae Subsidia 7), Bari.

Delgado Gómez, J. (1984): "La Biblia en la iconografía pétrea lucense", Boletín do Museo Provincial de Lugo 2, 85-118.

Deswarte, T. (2010): Une Chrétienté romaine sans pape, L'Espagne et Rome (586-1085), Paris.

Diego SAntos, F.

(1977): Historia de Asturias 3. Asturias romana y visigoda, Salinas.

(1979): "De la Asturias sueva y visigoda", Asturiensia Medievalia 4, 17-73.

(1985): Epigrafía romana de Asturias, Oviedo (=ERA).

(1994): Inscripciones medievales de Asturias, Oviedo.

DonAti, A. (COORD.), (1996): Dalla terra alle genti: la diffusione del cristianesimo nei primi secoli, Milano.

Duval, N. (1991): Naissance des arts chrétiens: atlas des monuments paléochrétiens de la France, Paris.

Eisenlohr, B. (1994): "Monogramme und Invokationszeichen in iberischen und frankischen Urkunden”, Signo. Revista de Historia de la Cultura Escrita 1, 35-50.

FARIOLI, R. (1977): Ravenna romana e bizantina, Ravenna.

Favreau, R. - Michaud, J. - Mora, B. (Dirs.), (1985): Corpus des Inscriptions de la France médiévale. 10, Paris.

FERnÁndez Conde, J.

(1972): La iglesia de Asturias en la Alta Edad Media, Oviedo.

(2000): La religiosidad medieval en España. I. Alta Edad Media (S.VII-X), Oviedo.

(2002): "Cristianización y simbología del poder en la época de la monarquía asturiana", [en] La época de la monarquía asturiana, Oviedo, 263-294.

Fernández Guerra, A. (1878): “Cantabria”, Boletín de la Sociedad Geográfica 4, 93-150.

FERNÁNDEZ OCHOA, C.

(1982): Asturias en la época romana, Madrid.

(1997): La muralla romana de Gijón (Asturias), Gijón.

(2003): El lenguaje de las piedras. La recuperación del Patrimonio Arqueológico de Gijón, Gijón.

(2010): Gijón Romano, Historia de Gijón, vol. 3, Oviedo.

Fernández OchoA, C. et alii

(1992): “Gijón en el período tardoantiguo: cerámicas importadas de las excavaciones de Cimadevilla", AEspA 65, 105-149.

(1997): "Proyecto Veranes. Arqueología e Historia en torno a la vía de la Plata en el concejo de Gijón (Asturias)", CuPAUAM 24, 253-278. 
(2005-2006): “La villa romana de Veranes (Gijón, Asturias). Aportaciones preliminares sobre la transformación funcional del asentamiento en la tardía Antigüedad", CuPAUAM 31-32, 137-194.

Fernández OchoA, C. - García Díaz, P. (1996): Las termas romanas de Campo Valdés, Gijón.

Fernández Ochoa, C. - García Díaz, P. - Zarzalejos Prieto, M. (2001): Excavaciones en Santa María de Lugo de Llanera (Asturias). Memoria de las Campañas de 1991 a 1995, Oviedo.

Fernández Ochoa, C. - Gil Sendino, F.

(1999): "Excavaciones arqueológicas en el yacimiento romano y medieval de Veranes (Cenero). Campañas de 1997 y 1998", Excavaciones Arqueológicas en Asturias (1995-1998), Oviedo, vol. 4, 175-186.

(2007): "El Torrexón de Veranes. Reflexiones sobre la transición al Medioevo en Asturias desde una perspectiva arqueológica", Excavaciones Arqueológicas en Asturias (19992002), Oviedo, vol. 5, 149-161.

(2007a): "La etapa final de Roma en Hispania: La villa de Veranes (Gijón, Asturias)", [en] J. Fernández Tresguerres (coord.), Astures y romanos. Nuevas perspectivas, Oviedo, 133 148.

(2007b): "El yacimiento romano-medieval de Veranes (Gijón, Asturias)", [en] L. Arias Páramo (coord.), Enciclopedia del Prerrománico en Asturias, Aguilar de Campoo, vol. II, 645-657.

(2008): "La villa romana de Veranes (Gijón, Asturias) y otras villas de la vertiente septentrional de la cordillera cantábrica", [en] C. Fernández Ochoa - V. García-Entero - F. Gil Sendino (eds.), Las villas romanas en el occidente del Imperio: arquitectura y función, Gijón, 435-479.

(2009): "El yacimiento romano y medieval de Veranes, Cenero (Gijón). Campañas 20032006”, Excavaciones Arqueológicas en Asturias 2003-2006, Oviedo, vol. 6, 283-302.

(2011): "Villae romanas en Asturias", [en] V. Revilla Calvo - J. R. González Pérez - M. Prevosti Monclús (eds.), Actes del Simposi: Les vil.les romanes a la Tarraconense (= Museu d'Arqueologia de Catalunya. Monografies 11), Barcelona, vol. II, 49-72.

Fernández OchoA, C. - Gil Sendino, F. - Del Hoyo, J. (2007): “Una inscripción y un boceto hallados en la villa romana de Veranes (Gijón, Asturias)", AEspA 80, 183-190.

Fernández OchoA, C. - Gil Sendino, F. - Orejas, A. (2004): "La villa romana de Veranes. El complejo rural tardorromano y el estudio del territorio", AEspA 77, 197-219.

Fernández Ochoa, C. - Gil Sendino, F. - Salido, J. - Zarzalejos, M. (2012): El horreum de la villa de Veranes. Primer testimonio material de un hórreo en Asturias (=Col. Arte y Humanidades, UNED), Madrid.

Fernández OchoA, C. - Morillo, A. - López Quiroga, J. (2005): “La dinámica urbana de las ciudades de la fachada noratlántica y del cuadrante noroeste de Hispania durante el Bajo Imperio y la Antigüedad tardía (siglos III a VII d.C.)", [en] VI Reunión de Arqueología Cristiana Hispánica, Barcelona, 95-119.

FERrua, A.

(1947): “Tavole da gioco", La Civiltà Cattolica 98, 134-142.

(1947a): "Tavole da gioco", La Civiltà Cattolica 98, 495-503.

FITA, F. (1894): “Excursiones epigráficas. De Monesterio a Mérida”, BRAH 25, 43-166.

Floriano Llorente, P. (1968): Colección diplomática del monasterio de San Vicente, Oviedo. 
Fontes, L. F. O. (1991-1992): "Salvamento arqueológico de Dume (Braga). Resultados das campanhas de 1989-90 e 1991-92", Cadernos de Arqueología, Serie II, 8-9, 199-200.

García Álvarez-Busto, A. (2006): "Poder y poblamiento en el territorio Gegione (Asturias) durante el Alto Medievo", Territorio, Sociedad y Poder 1, 129-156.

García Lagarreta, S. (1962): Colección de documentos de la catedral de Oviedo, Oviedo.

GARLAND, E.

(1988): "Le décor sculpté des églises romanes du Comminges. Première partie: le décor des portails. Recension des chrismes", Revue de Comminges CI(1), 15-31.

(1988a): "Le décor sculpté des églises romanes du Comminges. Recension des chrismes (suite)", Revue de Comminges CI (2), 161-172.

(1988b): "Le décor sculpté des églises romanes du Comminges. Recension des chrismes (fin)", Revue de Comminges CI (3), 321-333.

Gil Zubillaga, E. (1997): “Iconografía cristiana sobre sigillata tardía de Iruña/Veleia”, Isturitz $9,817-821$.

Girardet, K. M. (2010): Der Kaiser und sein Gott. Das Christentum im Denken und in der Religionspolitik Konstantins des Grossen, Berlin-New York.

Giuliani, R. - Tomassi, F. M. - Giannitrapani, M. - Ricciardi, M. (2001): "Nuove indagini nella catacomba della ex vigna Chiaraviglio sulla via Appia antica. Relazione delle campagne di scavo nella regione F (1997/1999)", Rivista di Archeologia Cristiana 77/1-2, 97-362.

Godoy, C. (1995): Arqueología y liturgia. Iglesias hispánicas (siglos IV al VIII), Barcelona.

GonzÁlez, J. M. (1979): “Gijón prerromano”, [en] El libro de Gijón, Gijón, 13-25.

González Blanco, A. - Velázquez, A. (2008): Los orígenes del Cristianismo en Lusitania, Mérida.

GonzÁlez Salinero, R. (2009): "La dimensión edificante del espacio sagrado: la arquitectura de culto cristiano en las fuentes escritas hispano-visigodas del siglo VII", [en] L. Caballero Zoreda - P. Mateos Cruz - M. A. Utrero Agudo (eds.), El siglo VII frente al siglo VII: Arquitectura (=Anejos de AEspA LI), Madrid, 11-30.

Gorostidi, D. (2010): Ager Tarraconensis 3. Les inscripcions romanes, Tarragona.

Grossi Gond, F. (1920): I monumenti cristiani dei primi sei secoli, v. I. Trattato di epigrafia cristiana latina e greca del mondo romano occidentale, Roma.

Guardia Pons, M. (1992): Los mosaicos de la Antigüedad Tardía en Hispania. Estudios de Iconografia, Barcelona.

Gutiérrez GonzÁlez, A.

(2003): Peñaferruz (Gijón). El castillo de Curiel y su territorio, Gijón.

(2007): "La formación del territorio de Asturias en el periodo de Monarquía asturiana", [en] L. Arias Páramo (coord.), Enciclopedia del prerrománico asturiano, Aguilar de Campoo, vol. I, 17-56.

(2008): "Las villae y la genésis del poblamiento medieval”, [en] C. Fernández Ochoa - V. García-Entero - F. Gil Sendino (eds.), Las villas romanas en el occidente del Imperio: arquitectura y función, Gijón, 215-238.

(2010): “Arqueología tardoantigua en Asturias. Una perspectiva de la organización territorial y del poder en los orígenes del Reino de Asturias”, [en] J. I. Ruíz de la Peña - J. Camino (coords), La Carisa y La Mesa. Causas políticas y militares del origen del Reino de Asturias, Oviedo, 53-83. 
HÜBNER, E.

(1871): Inscriptiones Hispaniae Christianae, Berolini (=IHC).

(1900): Inscriptionum Hispaniae Christianarum. Supplementum, Berolini.

Iglesias Gil, J. M. (1976): Epigrafía cántabra, Santander (=EC).

JimÉnez GARniCA, A. M. (1992): "La cultura visigoda en Asturias", [en] Historia de Asturias, Oviedo, vol. I, 253-272.

Jimeno Aranguren, R. (2006): “Aproximación al cristianismo primitivo en Navarra”, [en] J. Andreu (ed.), Navarra en la Antigüedad: propuesta de actualización, Pamplona, 287-322.

López Quiroga, J. - Rodríguez Martín, G. (2001): "El final de las villae en Hispania. La transformación de la pars urbana de las villae durante la Antigüedad Tardía", Portugalia XXI-XXII, 137-190.

López Rodríguez, J. R. (1982): “El primer crismón en Terra Sigillata Hispanica Tardía”, Boletín del Seminario de Estudios de Arte y Arqueología 48, 181-185.

Martín Valls, R. (1982): "Las necrópolis del castro de Yecla de Yeltes. Datos arqueológicos y epigráficos para su estudio", Zephyrus 34-35, 186-201.

Martínez Díez, G. - Rodríguez, F. (1992): La colección canónica hispana. V, Concilios hispanos: segunda parte, Madrid.

Mazzoleni, D. (1996): “L'epigrafia cristiana”, [en] Donati (coord.), 1996, 107-121.

Menéndez Bueyes, L. R. (2001): Reflexiones críticas sobre el origen del Reino de Asturias, Salamanca.

Mesplé, P.

(1970): "Les chrismes du département du Gers. Observation sur l'evolution et le groupement des chrismes au nord et au sud des Pyrénes", Mémoires de la Société Archéologique du Midi de la France XXXV, 71-88.

(1972): "Les chrismes du département du Gers (4 sèrie)", Bulletin de la Société Archéologique Historique et Littéraire du Gers 73, 392-397.

Muñoz Amilibia, A. M. (1982): “Cruz de bronce monogramática procedente de Cehegín”, [en] II Reunión Internacional de Arqueología Cristiana, Monserrat, 265-276.

NAVASCUÉs, J. M.

(1972): “Trío de estelas", Revista de la Universidad Complutense XXI/83, 149-183.

(1931): Colección de antigüedades que pertenecieron al Sr. Marqués de Monsalud, (=Museo Arqueológico Nacional. Nuevas adquisiciones en 1930), Madrid.

Nestori, A. (1985): "Ultimi lavori a Calepodio", Rivista di Archeologia Cristiana 41/3-4, 237-253.

OEPEN, A. (2012): Villa und christlicher Kult auf der Iberischen Halbinsel in in Spätantike und Westgotenzeit, Wiesbaden.

Pacheco Sampedro, R. - Sotelo Martín, E. (2001): "Crismones y símbolos invocativos cristianos hispano-visigodos”, [en] A. Alberte González - C. Macías Villalobos (eds.), Actas del Congreso Internacional "Cristianismo y tradición latina”, Madrid, 377-386.

PALOL, P.

(1967): Arqueología cristiana de la España romana, Madrid.

(1990): "Bronces cristianos de época romana y visigoda en España", [en] Los Bronces Romanos en España, Madrid, 137-152. 
Paris-Poulain, D. - Nardi Combescure, S. - Istria, D. (2009): Les premiers temps chrétiens dans le territoire de la France actuelle: hagiographie, épigraphie et archéologie. Nouvelles approches et perspectives de recherche, Rennes.

PeEK, W. (1955): Griegische Versinschriften I, Berlin.

Peña Cervantes, Y. (2000): "Reutilizaciones termales en el Noroeste de la provincia tarraconense", [en] C. Fernández Ochoa - V. García-Entero (eds.), Termas romanas en el occidente del Imperio, II Coloquio Internacional de Arqueología en Gijón, Gijón, 349-354.

Pérez Vilatela, L. (1995): “Grabados cristianos inéditos de Peñalba”, [en] IV Reunió d'Arqueologia Cristiana Hispanica, Lisboa, 203-210.

Peyrelade, L. (1979-1980): "Les chrismes dans les Hautes-Pyrénées”, Bulletin de la Société Ramond 1979-1980, 43-50.

Pitt-Rivers, G. (1966): The riddle of the 'labarum' and the origin of Christian symbols, London.

PodDI, M. (2009): "Le iscrizioni della regione già denominata di "Vigna Chiaraviglio" nel complesso di S. Sebastiano sulla Via Appia: note e osservazioni", Rivista di Archeologia Cristiana 85, 541-566.

RAmírez SÁdABA, J. L. (2003): "Epigrafía monumental cristiana en Extremadura”, [en] P. Mateos Cruz - L. Caballero Zoreda (eds.), Repertorio de arquitectura cristiana en Extremadura: época tardoantigua y altomedieval, Mérida, 271-291.

Ramírez SÁdaba, J. L. - Mateos, P. (2000): Catálogo de las inscripciones cristianas de Méri$d a$ (=Cuadernos Emeritenses 16), Mérida.

Recio Veganzones, A.

(1995): "La mártir Eulalia en la devoción popular. Prudencio primer promotor de su culto, peregrinaciones, expansión de sus reliquias e iconografía (ss. IV-VII)", [en] IV Reunió d'Arqueologia Cristiana Hispanica, Lisboa, 317-336.

(1978): “"Baetica' paleocristiana y visigoda: la antigua 'Nebrissa', hoy Lebrija”, Rivista di Archeologia Cristiana 54/1-2, 23-82.

(1979): “'Baetica' paleocristiana y visigoda: la antigua 'Nebrissa', hoy Lebrija”, Rivista di Archeologia Cristiana 55/1-2, 41-88.

Ripoll, G. - ARCE, J. (1999): "Transformación y final de las villae en Occidente siglos I-VII. Problemas y perspectivas", Arqueología y Territorio Medieval 8, 21-50.

Ripoll, G. - Velázquez, I. (1999): “Origen y desarrollo de las Parrochiae en la Hispania de la Antigüedad Tardía”, [en] Alle Origini della Parrocchia rurale (IV-VIII sec.), Città del Vaticano, 101-165.

Rodríguez Colmenero, A. (1987): "Inscripciones paleocristianas en el museo de Oviedo", Memorias de Historia Antigua VIII, 177-184.

Ruiz Asencio, J. M. (2005): "Precepto de Medema (Madrid, AHN, códices 1452B, frag. 13)", [en] Velázquez - Santonja, eds., 2005, 228-230.

SANTIAGo Fernández, J. (2004): "Materia y elementos iconográficos en las inscripciones cristianas de Mértola", Documenta \& Instrumenta 2, 193-226.

Sastre De Diego, I. (2010): Los primeros edificios cristianos de Extremadura. Sus espacios y elementos litúrgicos. Caelum in terra, Mérida.

SAyas AbengocheA, J. J. (1985): “Algunas consideraciones sobre la cristianización de los vascones”, Príncipe de Viana 46/174, 35-56. 
Schlunck, H. - Hauschild, TH. (1978): Denkmäler der frühchristlichen und westgotischen Zeit, Mainz am Rhein.

Schlunk, P. (1970): "Die Frühchristlichen Denkmäler aus dem Nord-Westen der Iberischen Halbinsel”, [en] A. García y Bellido (ed.), Legio VII Gemina, León, 475-509.

Testa, E. (1962): Il simbolismo dei giudeo-cristiani (=Publications of the Studium Biblicum Franciscanum 14), Jerusalén.

Thiede, C. P. (1996): “Le lingue e la tradizione testuale del primo cristianesimo", [en] Donati (coord.), 1996, 133-142.

Traviani, L. (2007): “La croce sulle monete da Costantino alla fine del Medioevo", [en] B. Ulianich (ed.), La Croce. Iconografia e interpretazione, Napoli, 7-40.

Valdés Gutiérrez, M. (1922): Antología Manuel de Valdés Gutiérrez, Cenero, Gijón (reed. 2005).

VelÁzQuez, I. (2004): Las pizarras Visigodas (entre el latín y su disgregación: la lengua hablada en Hispania, siglos VI-VIII), Salamanca.

VelázQUez, I. - SAntonja, M. (EDS.), (2005): En la pizarra. Los últimos hispanorromanos de la Meseta. Catálogo de la exposición, Burgos.

Vidal Álvarez, S. (2005): La escultura hispánica figurada de la Antigüedad Tardía (Siglos $I V$-VII), (=Corpus Signorum Imperii Romani, España 2), Murcia.

Villa VALDÉs, A. (2000): "Sobre el significado de algunos grabados rupestres asignados a la Edad del Bronce en Asturias", [en] Congreso Internacional de Arte Rupestre Europea, Vigo [edición en CD-Rom].

Vives, J. (1969): Inscripciones cristianas de la España romana y visigoda (=Monumenta Hispaniae sacra. Serie patrística 2), Barcelona (=ICERV).

VV. AA. (2000): Christianizing peoples and vonverting individuals (=International Medieval Research 7), Bruxelles.

YAmadA, J. (1999): “L'arcosolio dell'Hermes-Psicopompo nel cimitero di S. Sebastiano: qualche riflessione alla luce dei recenti restauri”, Rivista di Archeologia Cristiana 75/1-2, 281-305.

ZIAS, J. (1996): “La prima cristianità in Terrasanta”, [en] Donati (coord.), 1996, 44-48. 